\title{
ALFA-OXIDAÇÃO DE PROPIONATO ESTÁ ENVOLVIDA NA REDUÇÃO DA PRODUÇÃO DE PLÁSTICO BIODEGRADÁVEL EM \\ BURKHOLDERIA SACCHARI?
}

\author{
Dissertação apresentada ao \\ Instituto de Ciências Biomédicas da \\ Universidade de São Paulo \\ para a obtenção do Título de \\ Mestre em Ciências (Microbiologia)
}

Área de concentração: Microbiologia

Orientadora: Profa. Dra. Luiziana Ferreira da Silva 


\section{RESUMO}

CINTRA, ACSD. Alfa-oxidação de propionato está envolvida na redução da produção de plástico biodegradável em Burkholderia sacchari? [Dissertação]. São Paulo: Instituto de Ciências Biomédicas da Universidade de São Paulo; 2008.

Burkholderia sacchari é uma nova espécie bacteriana do solo brasileiro que tem a capacidade de crescer em sacarose e acumular grânulos intracelulares de poliésteres pertencentes à família dos polihidroxialcanoatos (PHA). Quando cultivado em sacarose, o homopolímero poli-3hidroxibutirato é acumulado por esta bactéria, que é usado como um plástico biodegradável e biocompatível. Quando sacarose e ácido propiônico são fornecidos como fontes de carbono, as células de B. sacchari acumulam o copolímero poli-3-hidroxibutirato-co-3-hidroxivalerato (P3HB-co-3HV). Entretanto, uma pequena porcentagem do ácido propiônico fornecido é convertido a unidades $3 \mathrm{HV}$ devido à eficientes vias catabólicas que convertem este substrato preferencialmente a biomassa, $\mathrm{CO}_{2}$ e água, reduzindo portanto a eficiência da produção do polímero. Ao menos duas vias do catabolismo de propionato foram previamente propostas em B. sacchari: $\alpha$-oxidação e ciclo do 2-metilcitrato (2MCC), sendo somente a última confirmada no nível molecular. Mutantes UV, obtidos anteriormente, foram incapazes de crescer em propionato (prp) e também apresentaram fenótipo afetado no crescimento em intermediários da $\alpha$-oxidação. No presente trabalho, após uma busca em bibliotecas genômicas de $B$. sacchari, uma delas construída também no presente trabalho, três diferentes fragmentos de DNA presentes nos clones $\mathrm{A}_{1}, \mathrm{P}_{1}$ e $\mathrm{P}_{2}$ foram capazes de restaurar o fenótipo prp + aos mutantes. Experimentos quantitativos revelaram que $\mathrm{A}_{1}$ somente restaurou parcialmente a conversão de propionato a unidades $3 \mathrm{HV}$ aos mutantes. $\mathrm{P}_{1}$ foi capaz de restaurar a capacidade de crescimento em propionato, e em outros intermediários da $\alpha$-oxidação, a um dos mutantes. Um DNA de $1.2 \mathrm{~Kb}$, subfragmento de $\mathrm{P}_{1}$, ainda capaz de complementar mutantes prp, foi subclonado e seqüenciado, demonstrando similaridade a seqüências de DNA codificadoras de reguladores transcricionais do tipo LysR de várias bactérias, incluindo espécies de Burkholderia. Regiões adjacentes a LysR em diferentes genomas de Burkholderia são anotados como codificadores de acil-CoA desidrogenases, ao lado de proposta acil-CoA transferases/carnitina desidrogenases e de uma permease do facilitador maior da superfamília MFS-1. Após confirmação das mesmas regiões adjacentes em B. sacchari e também a sua específica deleção, será possível provar a presença da via do catabolismo de propionato indicada neste trabalho.

Palavras-chave: Burkholderia sacchari, polihidroxialcanoatos, polímeros biodegradáveis, catabolismo de ácido propiônico, 3-hidroxivalerato (3HV). 


\begin{abstract}
CINTRA, ACSD. Is propionate alfa-oxidation involved in the reduction of biodegradable plastic production in Burkholderia sacchari? [Dissertation]. São Paulo: Instituto de Ciências Biomédicas da Universidade de São Paulo; 2008.

Burkholderia sacchari is a new bacterial species from Brazilian soil, able to grow in sucrose, accumulating intracellular granules of polyester belonging to the polyhydroxyalkanoate family (PHA). When cultivated on sucrose, the homopolymer poly-3-hydroxybutyrate is accumulated by this bacterium, which is used as biodegradable and biocompatible plastic. When sucrose and propionic acid are supplied as carbon sources, $B$. sacchari cells accumulate the copolymer poly-3-hydroxybutyrate-co-3-hydroxyvalerate (P3HB-co-3HV). However, a small percentage of the propionic acid supplied is converted to $3 \mathrm{HV}$ units, because efficient catabolic pathways convert this substrate preferentially to biomass, $\mathrm{CO}_{2}$ and water, thus reducing the efficiency of polymer production. At least two propionate catabolic pathways have been previously indicated in B. sacchari: $\alpha$-oxidation and the 2-methylcitric acid (2MCC), the latter confirmed at molecular level. UV mutants previously obtained were unable to grow in propionate (prp) and also showed the phenotype affected concerning grow on intermediates of propionate $\alpha$ oxidation. In the present work, after a screening in B. sacchari genomic libraries, one of them constructed also in the present work, the prp ${ }^{+}$phenotype was restored to the mutants by three different DNA fragments harbored by clones $\mathrm{A}_{1}, \mathrm{P}_{1}$ and $\mathrm{P}_{2}$. Quantitative experiments revealed that $A_{1}$ restored only partially the quantitative conversion of propionate to $3 \mathrm{HV}$ units to the mutants. $P_{1}$ restored the ability to grow in propionate and in other intermediates of $\alpha$-oxidation to one prp mutant. A DNA $1.2 \mathrm{~Kb}$ subfragment of $\mathrm{P}_{1}$, still able to complement prp mutants, was subcloned and sequenced, showing similarity to DNA sequences encoding to LysR-type transcriptional regulators of various bacteria, including Burkholderia species. Adjacent regions to LysR in different genomes of Burkholderia are annotated as encoding to acyl-CoA dehydrogenases, neighboring a predicted acyl-CoA transferases/carnitine dehydratase and a permease of the major facilitator superfamily MFS-1. After confirmation of the same adjacent regions in $B$. sacchari and also their especific deletion, it will be possible to prove the presence of the pathway indicated here in the catabolism of propionate.
\end{abstract}

Key words : Burkholderia sacchari, polyhydroxyalkanoates, biodegradable polymers, propionic acid catabolism, 3-hydroxyvalerate (3HV). 


\section{INTRODUÇÃO E JUSTIFICATIVA}

Nas últimas décadas, o acúmulo de lixo plástico não biodegradável se tornou uma preocupação ambiental recorrente. No mundo, são consumidos anualmente aproximadamente 140 milhões de toneladas de plástico. Para o processamento deste material, são ainda empregadas cerca de 150 milhões de toneladas de combustíveis fósseis, cuja substituição é difícil (Suryiamongkol et al., 2007). Neste cenário, a busca por materiais biodegradáveis, produzidos a partir de matérias-primas renováveis tem sido o objeto de estudo em diversos países, entre os quais, o Brasil apresenta boas perspectivas de sucesso (Nonato et al., 2001, Pradella, 2006). Entre as alternativas em estudo, destaca-se um grupo de biopolímeros, genericamente denominados polihidroxialcanoatos (PHA). PHA são bioplásticos naturais sintetizados e catabolizados por vários organismos. Constituem uma família de poliésteres acumulados intracelularmente por microrganismos na forma de grânulos e que apresentam importância biotecnológica por serem aplicados na produção de plásticos e elastômeros biodegradáveis e biocompatíveis (Steinbüchel \& Valentin, 1995, Madison \& Huisman, 1999, Gomez \& Bueno Netto, 2001), aplicáveis na confecção de embalagens diversas, além de produtos farmacêuticos e médicos (Holmes, 1985, 1988; Valappil et al., 2006). As aplicações dependem de suas propriedades, assim sendo, diversos estudos vêm sendo desenvolvidos para avaliar as propriedades dos PHA puros ou combinados a outros materiais (Caraschi \& Leão, 1999, Caraschi et al., 2003, Quental \& Felisberti, 2001, Rodríguez et al., 2003, Pachekoski et al., 2003, Formolo et al., 2003, Bucci, 2003, Silva et al., 2007).

Burkholderia sacchari IPT/LFM 101 é uma linhagem bacteriana, Gram negativa, isolada de solo brasileiro num programa de seleção de microrganismos capazes de produzir PHA a partir de sacarose, matéria-prima abundante no país (Gomez, 1994; Gomez et al., 1996). Entre diferentes linhagens testadas, esta se destacou por sua capacidade de rápido crescimento nesta fonte de carbono, bem como acúmulo de altas porcentagens de PHA no seu interior (Gomez et al., 1996; Gomez et al., 1997). Estudos taxonômicos, envolvendo laboratórios do Brasil, Alemanha e Bélgica, indicaram que a linhagem IPT/LFM 101 representa uma nova espécie no gênero Burkholderia, tendo sido então proposto o nome Burkholderia sacchari 
(Brämer et al., 2001; Silva et al., 2001 a, b). Ao ser cultivada em sacarose, sob limitação de um nutriente essencial ao crescimento como nitrogênio, fósforo, oxigênio, etc., B sacchari acumula o homopolímero poli-3-hidroxibutirato (P3HB) e, ao se oferecer como co-substrato o propionato, a bactéria acumula um copolímero de poli-3-hidroxibutirato-co-3-hidroxivalerato (P3HB-co-3HV) (Silva, 1998) (Figura 1). P3HB e P3HB-co-3HV estão entre os PHA mais estudados e sua produção industrial foi viabilizada (Bueno Netto et al., 1993, Nonato et al., 2001, Ereno et al., 2007), em virtude do seu potencial como substituto dos plásticos convencionais, em aplicações que vão desde a produção de embalagens, até aplicações médicas que requerem biocompatibilidade e maior grau de pureza (de Koning et al., 1995, 1996).

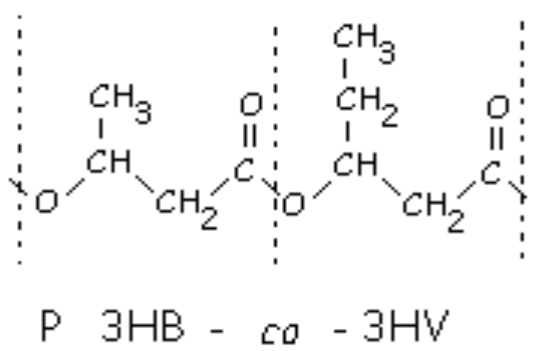

Figura 1 Estrutura do copolímero de poli-3-hidroxibutirato-co-3- hidroxivalerato (P3HB-co-3HV)

A incorporação de unidades $3 \mathrm{HV}$ pode ser obtida pelo fornecimento de valerato ou propionato como co-substrato, gerando um copolímero mais flexível com maior variedade de aplicações (Holmes, 1985). O co-substrato mais comumente adicionado é o propionato; entretanto, dois fatores constituem dificuldades operacionais ao seu uso: o seu custo, aproximadamente três vezes maior que o da sacarose, e o seu baixo aproveitamento por bactérias para a síntese do copolímero. Dada a eficiência de crescimento de $B$. sacchari em sacarose, esta bactéria foi testada também frente a uma mistura de sacarose e propionato sem, no entanto, ter demonstrado maior eficiência na conversão deste último em unidades $3 \mathrm{HV}$ de modo similar ao que ocorre com outros gêneros (Silva, 1998). Assim, foram obtidos por irradiação ultravioleta, mutantes desta bactéria incapazes de crescer em propionato, mas ainda capazes de utilizá-lo para a produção de 3HV. Os mutantes foram classificados fenotipicamente quanto à capacidade de crescer em intermediários da $\alpha$ oxidação tendo sido classificados em quatro grupos (mutantes prp) (Tab. 1). Os resultados de avaliação da eficiência dos mutantes na geração de unidades $3 \mathrm{HV}$ a 
partir de propionato mostraram um aumento de até oito vezes sobre este fator de conversão de propionato a unidades 3HV, definido como $\mathrm{Y}_{3 \mathrm{HV} / \mathrm{prp}}$ (Silva et al., 1996, Silva, 1998, Silva \& Gomez, 1998, Silva et al., 2000). Os valores de Y elevaram-se de $0,10 \mathrm{~g} / \mathrm{g}$ na linhagem selvagem para até $0,80 \mathrm{~g} / \mathrm{g}$ em linhagens selvagens indicando seu alto potencial para uso industrial em processo desenvolvido pelo Instituto de Pesquisas Tecnológicas do Estado de São Paulo S.A - IPT - e licenciado para produção industrial (Bueno Netto et al., 1993, Silva \& Gomez, 1998).

Tabela 1. Grupos fenotípicos de mutantes de B. sacchari obtidos, considerando a utilização de intermediários da $\alpha$-oxidação de propionato (Silva et al., 1996).

\begin{tabular}{lcccccc}
\multicolumn{2}{l}{ LINHAGEM/GRUPO } & \multicolumn{5}{c}{ FENÓTIPO } \\
\hline Selvagem & & $\mathrm{sac}^{+}$ & $\mathrm{acet}^{+}$ & $\mathrm{prp}^{+}$ & $\mathrm{lac}^{+}$ & $\mathrm{pir}^{+}$ \\
Grupo & I & $\mathrm{sac}^{+}$ & $\mathrm{acet}^{-}$ & $\mathrm{prp}^{-}$ & $\mathrm{lac}^{-}$ & $\mathrm{pir}^{-}$ \\
Grupo & II & $\mathrm{sac}^{+}$ & $\mathrm{acet}^{-}$ & $\mathrm{prp}^{-}$ & $\mathrm{lac}^{2}$ & $\mathrm{pir}^{-}$ \\
Grupo & III & $\mathrm{sac}^{+}$ & $\mathrm{acet}^{-}$ & $\mathrm{prp}^{-}$ & $\mathrm{lac}^{+}$ & $\mathrm{pir}^{-}$ \\
Grupo & IV & $\mathrm{sac}^{+}$ & $\mathrm{acet}^{+}$ & $\mathrm{prp}^{-}$ & $\mathrm{lac}^{+}$ & $\mathrm{pir}^{+}$ \\
\hline
\end{tabular}

sac: meio contendo sacarose; acet: meio contendo acetato; prp: meio contendo propionato; lac: meio contendo lactato; pir: meio contendo piruvato;

'crescimento; 'ausência de crescimento

Uma análise do desempenho dos mutantes obtidos mostra que o valor de $\mathrm{Y}_{3 \mathrm{HV} / \text { Prop }}=0,10 \mathrm{~g} / \mathrm{g}$, apresentado pela linhagem selvagem, foi aumentado para $\mathrm{Y}_{3 \mathrm{HV} / \text { Prop }}=0,35 \mathrm{~g} / \mathrm{g}$ e $\mathrm{Y}_{3 \mathrm{HV} / \text { Prop }}=0,80 \mathrm{~g} / \mathrm{g}$ em mutantes afetados no consumo de intermediários da $\alpha$-oxidação e em um outro grupo não afetado no uso de tais intermediários (Tab. 2), respectivamente. Tais valores significam uma redução de até $53 \%$ dos custos com fonte de carbono na produção de polímero para plástico biodegradável (Silva, 1998). Não se observou a formação de 3HV a partir de substrato não relacionado nestes mutantes (Silva et al., 2000), o que indica que $3 \mathrm{HV}$ é formado apenas a partir de ácido propiônico. Em biorreator, em função da estratégia de cultivo adotada, o fator de conversão de propionato em unidades 3HV do mutante IPT/LFM 189 aumentou de $\mathrm{Y}_{3 \mathrm{HV} / \text { Prop }}=0,80 \mathrm{~g} / \mathrm{g}$ para $\mathrm{Y}_{3 \mathrm{HV} / \text { Prop }}=1,20 \mathrm{~g} / \mathrm{g}$ na fase de acúmulo de polímero (Silva et al., 2000). 
Tabela 2. Eficiência de mutantes de Burkholderia sacchari LFM 101 na conversão de propionato a unidades $3 \mathrm{HV}$ (Silva, 1998; Silva et al., 2000)

\begin{tabular}{|c|c|c|c|c|c|c|}
\hline LINHAGEM & GRUPO & FENÓTIPO* & $\begin{array}{c}\text { PHA } \\
(\%) \\
\end{array}$ & $\begin{array}{c}3 H B \\
(m o l \%) \\
\end{array}$ & $\begin{array}{c}3 H V \\
(m o l \%) \\
\end{array}$ & $\begin{array}{c}Y_{3 H V / P r o p} * * \\
(g / g)\end{array}$ \\
\hline LFM $101^{a}$ & selvagem & $\operatorname{sac}^{+}$, acet $^{+}, \operatorname{prp}^{+}, \operatorname{lac}^{+}$, pir $^{+}$ & 37.58 & 93.83 & 6.2 & 0.10 \\
\hline LFM 177 & & & 31.39 & 88.6 & 11.4 & 0.14 \\
\hline LFM 178 & & & 39.20 & 87.9 & 12.1 & 0.15 \\
\hline LFM 179 & & & 23.28 & 83.3 & 16.7 & 0.10 \\
\hline LFM 180 & $\mathbf{I}$ & $\mathrm{sac}^{+}, \mathrm{acet}^{-}, \mathrm{prp}^{-}, \mathrm{lac}^{-}, \mathrm{pir}^{-}$ & 24.16 & 74.9 & 25.1 & 0.21 \\
\hline LFM 181 & & & 23.66 & 82.5 & 17.5 & 0.10 \\
\hline LFM 182 & & & 28.29 & 83.3 & 16.7 & 0.14 \\
\hline LFM 183 & & & 43.17 & 84.1 & 15.9 & 0.34 \\
\hline LFM 184 & & & 34.52 & 78.8 & 21.2 & 0.27 \\
\hline LFM 185 & & & 40.47 & 82.6 & 17.4 & 0.35 \\
\hline LFM 186 & II & $\mathrm{sac}^{+}$, acet, prp$^{-}$, lac $^{?}$, pir $^{-}$ & 42.14 & 82.4 & 17.6 & 0.34 \\
\hline LFM 187 & & & 34.72 & 79.7 & 20.3 & 0.30 \\
\hline LFM 188 & & & 34.56 & 91.8 & 8.2 & 0.16 \\
\hline LFM 198 & & & 43.27 & 82.3 & 17.7 & 0.35 \\
\hline LFM 190 & III & $\mathrm{sac}^{+}$, acet $^{-}, \mathrm{prp}^{-}, \mathrm{lac}^{+}$, pir $^{-}$ & 44.19 & 80.1 & 19.9 & 0.37 \\
\hline LFM 191 & & & 36.69 & 90.3 & 9.7 & 0.16 \\
\hline LFM 189 & & & 25.8 & 44.7 & 55.3 & 0.81 \\
\hline LFM 192 & & & 7.67 & 48.5 & 51.5 & 0.35 \\
\hline LFM 193 & & & 27.96 & 31.7 & 68.3 & 0.70 \\
\hline LFM 194 & IV & $\mathrm{sac}^{+}, \mathrm{acet}^{+}, \mathrm{prp}^{-}, \operatorname{lac}^{+}, \mathrm{pir}^{+}$ & 25.16 & 41.4 & 58.6 & 0.77 \\
\hline LFM 195 & & & 32.39 & 39.0 & 61.0 & 0.81 \\
\hline LFM 196 & & & 31.81 & 33.2 & 66.8 & 0.78 \\
\hline LFM 197 & & & 29.35 & 33.5 & 66.5 & 0.73 \\
\hline
\end{tabular}

*Grupos fenotípicos de mutantes de B. sacchari obtidos, considerando a utilização de intermediários da alfa-oxidação de propionato; ** $\mathrm{Y}_{3 \mathrm{HV} / \text { Prop }}$ : Fator de conversão de ácido propiônico em unidades $3 \mathrm{HV}(\mathrm{g} / \mathrm{g})$.

Experimento representativo de 4 repetições, nas quais foram observados valores de $\mathrm{Y}_{3 \mathrm{HV} / \text { Prop }}=0.099 \pm 0.004 \mathrm{~g} / \mathrm{g}$;

Posteriormente, foi demonstrado que a conversão de propionato em $3 \mathrm{HV}$ pelo mutante IPT/LFM 189 pode ser ainda maior pelo emprego de técnicas de Engenharia Bioquímica, nas quais se controlam a vazão de alimentação da mistura de substratos para dentro do biorreator, bem como a razão sacarose/propionato empregada para o crescimento e acúmulo de PHA com o mutante IPT/LFM 189 (Rocha, 2002, Rocha et al., 2002, Rocha et al., 2007).

Ainda com o objetivo de melhorar e conhecer esta linhagem, foi obtida outra classe de mutantes incapazes de despolimerizar PHA intracelularmente (Filipov et al., 2001). 
Estes estudos fisiológicos e moleculares de mutantes prp de B. sacchari permitiram sugerir que a baixa conversão de propionato a $3 \mathrm{HV}$ pela via de síntese de polímero resulta da existência de pelo menos duas vias do catabolismo que competem, e são mais eficientes, por este substrato: $\alpha$-oxidação e o ciclo de 2metilcitrato (2MCC) (Silva et al., 2000, Gregório et al., 2001). No entanto, a proposição desta primeira via foi baseada apenas em evidências fenotípicas de mutantes estudados. Já a existência do $2 \mathrm{MCC}$ foi comprovada em $B$. sacchari por estudos moleculares (Brämer et al., 2002). Embora diversas vias de catabolismo de propionato tenham sido propostas na literatura, o $2 \mathrm{MCC}$ é a única comprovada no nível molecular, tendo sido descrita em bactérias no final da década passada (Textor et al., 1997).

No que se refere aos mutantes afetados na utilização de intermediários da $\alpha$ oxidação (grupos I, II e III da Tab. 1), especulou-se que esta possível via poderia assumir um papel mais importante sob condições de crescimento celular, e não de acúmulo, uma vez que $90 \%$ dos mutantes prp obtidos em estudos anteriores aprestaram este fenótipo (Silva et al., 2000). Além destas características fenotípicas e da alteração dos valores de $\mathrm{Y}_{3 \mathrm{HV} / \mathrm{Prop}}$, sabe-se que muitos desses mutantes não foram complementados por fragmentos de DNA genômico de B. sacchari portadores de regiões de genes do $2 \mathrm{MCC}$, nem por outras regiões capazes de complementar outros mutantes prp do grupo IV (Cintra et al., 2005). Outro dado a ser considerado é que os resultados de eficiência de conversão de propionato a unidades $3 \mathrm{HV}$ dos mutantes afetados no $2 \mathrm{MCC}$ e na $\alpha$-oxidação indicam que a inativação de ambas as vias poderia resultar na geração de mutantes apresentando valores próximos ao máximo teórico de $\mathrm{Y}_{3 \mathrm{HV} / \text { Prop }}$ calculado em 1,35 g/g (Silva et al., 1996, Silva et al., 2000).

Neste contexto, este trabalho estudou os mutantes dos grupos I, II e III, afetados na utilização de intermediários da $\alpha$-oxidação, com o intuito de identificar a natureza da modificação por eles sofrida. Para isso, uma biblioteca genômica da linhagem selvagem de $B$. sacchari foi construída para se realizar uma busca de fragmentos de DNA genômico capazes de restituir o fenótipo prp aos mutantes em estudo. Tais fragmentos foram caracterizados, subclonados e seqüenciados a fim de trazer maiores evidências moleculares da presença ou não de uma outra possível via do catabolismo de propionato em B. sacchari. 


\subsection{Objetivo}

O presente trabalho estudou mutantes de B. sacchari incapazes de crescer em propionato ( $\left.\operatorname{prp}^{-}\right)$e afetados na utilização de intermediários da $\alpha$-oxidação, mas ainda capazes de acumular P3HB-co-3HV, buscando obter ferramentas que permitam trazer evidências moleculares da presença ou não desta via como parte do catabolismo deste substrato nesta linhagem microbiana.

Para isto, o plano de trabalho consistiu de:

- Confirmação da caracterização fenotípica e reclassificação dos mutantes prp dos grupos I, II e III de B. sacchari;

- Construção de uma biblioteca genômica da linhagem selvagem de $B$. sacchari;

- Clonagem de fragmentos de DNA genômico capazes de restituir o fenótipo prp a mutantes em estudo de B. sacchari;

- Caracterização, subclonagem e seqüenciamento dos fragmentos obtidos. 


\section{SÍNTESE DA BIBLIOGRAFIA FUNDAMENTAL}

\subsection{Polihidroxialcanoatos e sua produção no país}

PHA compõem um grupo bastante diversificado de poliésteres acumulados por grande número de bactérias, sob condições especiais de cultivo, na forma de grânulos intracelulares (Steinbüchel \& Valentin, 1995). Os grânulos intracelulares de PHA são formados quando há limitação de um ou mais elementos essenciais ao crescimento bacteriano, como nitrogênio, fósforo ou magnésio, e são usados como fontes de energia, equivalentes redutores e de carbono quando esses elementos essenciais voltam a ser fornecidos, permitindo a multiplicação celular a partir da reserva polimérica (Anderson \& Dawes, 1990; Kahar et al., 2004). Recentemente, o significado ecológico e agrícola dos PHA para bactérias foi revisto, enfatizando o seu papel estratégico como fator de sobrevivência de microorganismos sob estresse em diversos ambientes (Kadouri et al., 2005). Quando extraídos do interior das células, PHA constituem materiais com propriedades termoplásticas e/ou elastoméricas, são insolúveis em água, enantiômeros puros, não tóxicos, piezoelétricos e exibem um alto grau de polimerização e pesos moleculares de até vários milhões de Daltons (Steinbüchel \& Hein, 2001). Em função destas características, sua produção e aplicabilidade vêm sendo estudadas em todo o mundo (Byrom, 1990, Madison \& Huisman, 1999, Sudesh et al, 2001, Nonato et al., 2001, Pradella, 2006, Silva et al., 2007). Estas características, associadas principalmente à sua biodegradabilidade e biocompatibilidade, fazem com que estes materiais sejam uma alternativa ambientalmente correta ao uso dos plásticos de origem petroquímica dado o seu impacto ambiental.

No Brasil, os mais diversos aspectos têm sido estudados. Foram isolados e caracterizados novos microrganismos capazes de utilização de diversas matériasprimas para a produção de PHA com diferentes composições monoméricas. Diversas linhagens bacterianas foram modificadas geneticamente para melhorar sua capacidade de utilização de novas matérias-primas, bem como sua capacidade de acúmulo quali e quantitativo. Este desenvolvimento no país foi recentemente revisto por Silva e colaboradores (2007). 
Isto se torna especialmente relevante pelo fato de que os nichos de aplicação de PHA dependem de suas propriedades físicas e químicas, determinadas pela composição monomérica, que por sua vez, depende da capacidade metabólica do organismo produtor e da matéria-prima (substrato) a ele oferecida, como destacados na Figura 2 (Rehm \& Steinbüchel ,1999; Gomez et al., 2005).

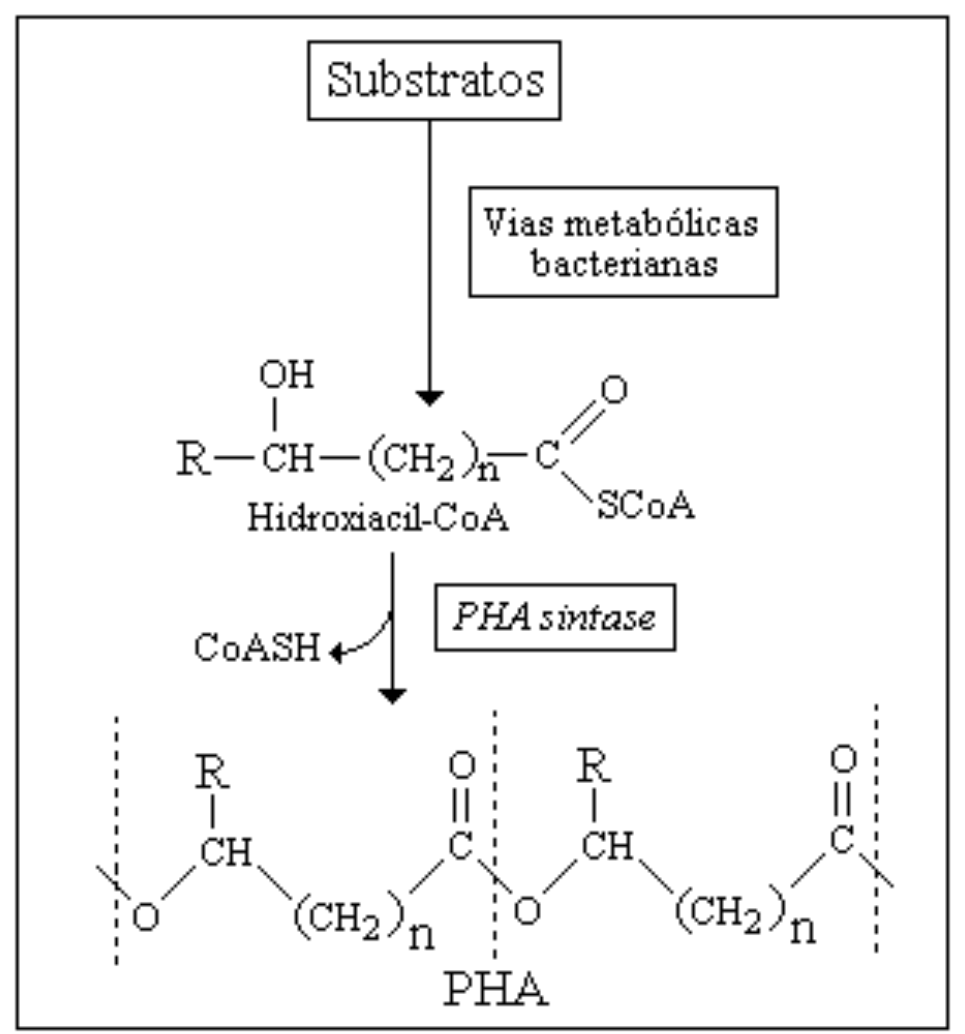

Figura 2. Esquema da síntese de PHA em bactérias. Os quadros destacam os pontoschave para modificar a composição monomérica dos PHA que influi nas suas propriedades e conseqüentes aplicações (Gomez et al., 2005)

A partir de 1992, a produção de alguns tipos de PHA vem sendo estudada, destacando-se, por suas propriedades, P3HB e P3HB-co-3HV. Encontram-se em estudo o uso de matérias-primas renováveis pela agricultura, tais como sacarose, melaço, hidrolisado de bagaço de cana (Bueno Netto et al., 1993, Gomez \& Bueno Netto, 1997; Silva, 2000; Gomez \& Bueno Netto, 2001, Silva et al., 2002, Silva et al., 2004). Um dos resultados mais importantes deste desenvolvimento no país é a produção em escala piloto, que se iniciou empregando-se derivados da cana-de-açúcar (Nonato et al., 2001). Outro resultado importante, foi o isolamento e identificação da 
nova espécie de bactéria Gram-negativa Burkholderia sacchari IPT/LFM 101 (Brämer et al., 2001) mais eficiente e, recentemente, melhorada para a incorporação de unidades $3 \mathrm{HV}$ a partir de propionato, bem como sua capacidade de usar xilose e hidrolisado de bagaço de cana-de-açúcar (Silva et al., 2002, Lopes et al., 2005).

Embora os PHA sejam conhecidos há décadas e seu potencial para algumas aplicações tenha sido demonstrado, em outros países do mundo em que sua produção foi estudada, houve relativamente pouca efetividade na transferência da tecnologia para a produção em grande escala. Os fatores que influíram neste cenário vão desde a dificuldade de expressão dos genes bacterianos codificadores em organismos de potencial maior produtividade, como as plantas (Poirier et al., 1992, 1995, ISBP 2002), até a necessidade de grande quantidade de combustível fóssil para transporte, separação e purificação, anulando assim o impacto ambiental por sua biodegradabilidade (Gerngross \& Slater, 2000).

Uma análise deste conhecimento acumulado no país permite apontar como alvo atual o controle destes diferentes aspectos da produção de PHA para assim, uma vez determinada uma propriedade necessária a uma dada aplicação, modular a sua composição monomérica, de sorte a se produzirem polímeros sob medida para aplicações estratégicas, a partir do controle dos fluxos metabólicos do microrganismo produtor, bem como das estratégias de produção em biorreator, num trabalho intrinsecamente multidisciplinar.

No cenário mundial, para produção de PHA a redução de custos é um fator que tem sido o alvo das diversas iniciativas e estudos. Assim, a obtenção de microrganismos, recombinantes ou não, com maior eficiência de produção, capazes de utilização de resíduos agro-industiais, melhoramento dos fluxos metabólicos e de processos de engenharia estão entre as estratégias abordadas (Li et al., 2007). Estudos para modificação da estrutura de PHA têm sido desenvolvidos para alterar suas propriedades, ampliando suas possibilidades de aplicação médica e industrial (Hazer \& Steinbüchel, 2007).

\subsection{Síntese de PHA em bactérias}

Embora um grande número de monômeros diferentes já tenha sido detectado como constituinte de PHA, convém destacar que a síntese e incorporação destes 
monômeros dependem do fornecimento de um substrato adequado, que possa ser convertido no hidroxiacil-CoA desejado, através das vias metabólicas existentes na célula bacteriana. Além disso, é necessário que a célula bacteriana contenha uma enzima PHA sintase, que seja capaz de incorporar o hidroxiacil-CoA gerado ao poliéster em formação (Gomez, 1994), já destacados na Figura 1.

Em diversas bactérias, a partir de acetil-CoA obtida do catabolismo de carboidratos, por exemplo, a síntese do homopolímero 3HB ocorre envolvendo a ação de três enzimas (Oeding \& Schlegel, 1973; Senior \& Dawes, 1973). Primeiro, por ação da 3-cetotiolase, duas moléculas de acetil-CoA se condensam, gerando acetoacetil-CoA. Esta, a seguir sofre uma redução, formando 3-hidroxibutiril-CoA por ação da acetoacetil-CoA redutase. A PHA sintase, finalmente, incorpora cada molécula de 3-hidroxibutiril-CoA à cadeia polimérica em crescimento. Na presença de um co-substrato, como o propionato, por exemplo, uma molécula de propionilCoA poderá então se condensar com uma de acetil-CoA e, seguindo as etapas posteriores, formar 3-hidroxivaleril-CoA a ser incorporada pela PHA sintase para formar o copolímero P3HB-co-3HV (Figura 3).

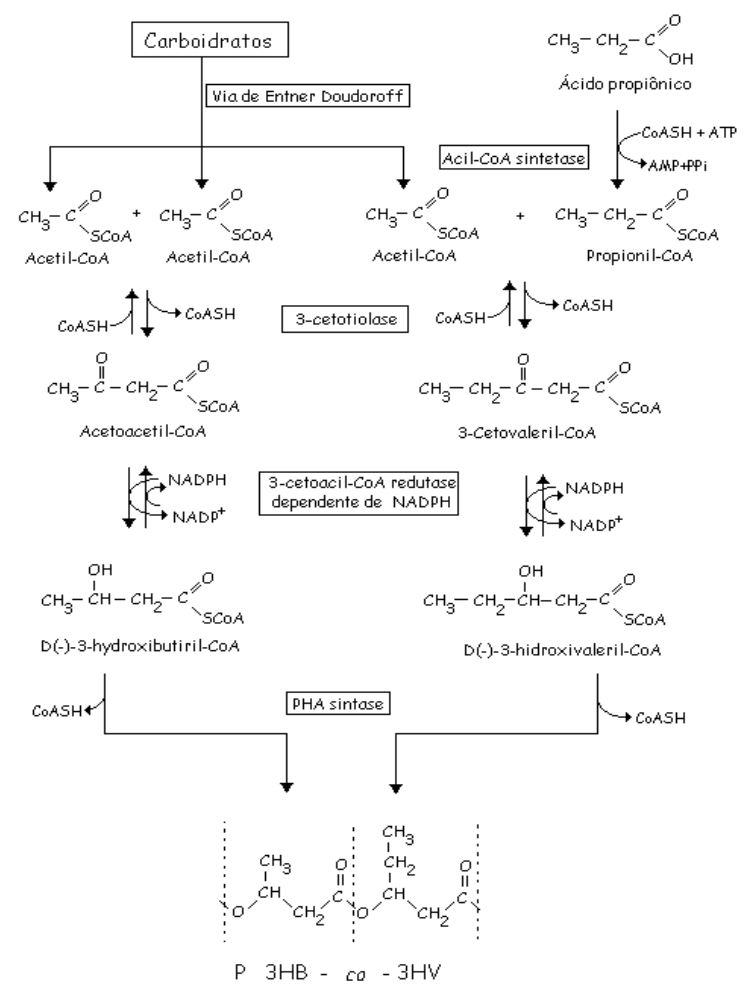

Figura 3. Síntese de P3HB-co-3HV a partir de carboidratos e ácido propiônico em Rastonia eutropha (Steinbüchel e Pieper, 1992). 
Embora a incorporação de unidades $3 \mathrm{HV}$ seja facilmente conseguida, fornecendo-se ácido propiônico ao cultivo bacteriano na fase de acúmulo (Doi et al., 1987), a eficiência de conversão deste substrato em unidades $3 \mathrm{HV}$ é, em geral, baixa, representando cerca de $10 \%$ do valor máximo teórico, que é de 1,35 gramas de $3 \mathrm{HV}$ por grama de ácido propiônico consumido (Gomez et al., 1996), caso todo propionato fornecido gere propionil-CoA, condensando-se com acetil-CoA proveniente exclusivamente de carboidratos (Figura 3).

A síntese de $\mathrm{P} 3 \mathrm{HB}-\mathrm{co}-3 \mathrm{HV}$ a partir de acetil-CoA e propionil-CoA é catalisada por uma $\beta$-cetotiolase, uma 3-cetoacil-CoA redutase NADPH-dependente e uma PHA sintase. Em R. Eutropha foi demonstrada a existência de três $\beta$-cetotiolases codificadas por genes $p h a A$, que codifica a enzima $\beta$-cetovaleril-CoA e $b k t B$, que demonstrou grande importância para a síntese de unidades $3 \mathrm{HV}$, visto que em estudo com linhagens de E. coli recombinante, a quantidade de unidades $3 \mathrm{HV}$ incorporadas no PHA, produzido a partir de propionato, muda signitivamente na presença ou ausência deste gene no genoma da bactéria (Slater et al., 1998).

A baixa eficiência nesta conversão, observada na maioria das bactérias, pode ser atribuída à existência de vias bastante eficientes de catabolismo deste substrato (Sprat et al., 1981), que conduzem uma importante parcela para a síntese de unidades $3 \mathrm{HB}$ ou $\mathrm{CO}_{2}$, precedida, portanto, da formação em maior proporção de acetil-CoA e não propionil-CoA.

Quando ácido propiônico é fornecido a Ralstonia eutropha como única fonte de carbono, o polímero resultante possui cerca de $45 \mathrm{~mol} \%$ em unidades 3HV (Doi et al., 1987; Anderson \& Dawes, 1990). Supondo-se que um polímero contendo 50 mol\% de unidades $3 \mathrm{HV}$ fosse formado, isto significaria que pelo menos $3 / 4$ do ácido propiônico fornecido teria se convertido a acetil-CoA (1/4 dos quais se condensaria com propionil-CoA para formar unidades $3 \mathrm{HV}$ e $2 / 4$ se condensariam na forma de acetil-CoA, aos pares, para formar unidades 3HB). Esta observação assume grande importância industrial, já que o ácido propiônico é um substrato relativamente caro para a produção de PHA, tendo sido desenvolvidos programas de obtenção de mutantes mais eficientes na canalização de propionato a unidades 3HV (Byrom, 1990, Sartori,1998; Silva, 1998, Silva et al., 2000). Para a obtenção de mutantes mais eficientes na conversão de propionato a unidades $3 \mathrm{HV}$, é de fundamental importância o conhecimento das vias metabólicas envolvidas no catabolismo deste substrato e que 
podem atuar de modo competitivo com a via de síntese de $\mathrm{P} 3 \mathrm{HB}-\mathrm{co}-3 \mathrm{HV}$, como será discutido a seguir.

\subsection{Catabolismo de propionato em diferentes organismos}

O fato do estudo do catabolismo de propionato apresentar um vínculo com a produção de plásticos biodegradáveis, não faz com que necessariamente apenas seja relevante para este tema. Assim, o conhecimento de outras abordagens para o estudo do metabolismo (degradação e síntese) deste componente pode ser útil para a comparação das vias conhecidas e das ferramentas empregadas.

$\mathrm{O}$ estudo do metabolismo de propionato tem assumido grande importância tanto em eucariotos como em procariotos. Em humanos, propionato é formado em decorrência da degradação de uma série de compostos oriundos da dieta, como treonina, metionina, isoleucina e valina, ácidos graxos de cadeia ímpar, colesterol e outros metabólitos. Deficiências no seu catabolismo levam a doenças como acidemias que podem ser bastante severas levando à morte já no primeiro dia de vida (Fenton \& Rosenberg,1995, Ugarte et al., 1999, Chloupková et al., 2000) . Em ruminantes, propionato é gerado como resultado da fermentação de carboidratos por diversos organismos e, junto com acetato, constitui fonte de energia para estes animais. É também produzido e consumido em ambientes metanogênicos (Stams et al., 1998). Ácido propiônico também pode ser produzido por fermentação de amido ou açúcar por Propionibacterium acidipropionici (Carrondo et al., 1988, Blanc \& Goma, 1989, Raecker et al., 1992) e pode ser utilizado para fragrâncias e agentes flavorizantes e conservantes.

Em bactérias, o catabolismo de propionato vem sendo estudado por ser o último composto oriundo da degradação de ácidos graxos de cadeia ímpar através da $\beta$-oxidação, tendo uma estrutura que não é alvo das reações de degradação de ácidos graxos ímpares de cadeia maior que a ele deram origem. Recentemente, o uso de propionato, juntamente com açúcares, adquiriu importância na obtenção de polihidroxialcanoatos (PHA), polímeros biodegradáveis, como P3HB-co-3HV, justamente para introduzir a fração $3 \mathrm{HV}$ e melhorar as propriedades do polímero (Steinbüchel, 1991). Alguns microrganismos, no entanto, se mostraram capazes de sintetizar polímero com unidades $3 \mathrm{HV}$ a partir de substrato não relacionado 
estruturalmente a este monômero. Este fato despertou o interesse pelo estudo de vias capazes de fornecer propionil-CoA para a síntese de unidades 3HV em Nocardia coralina, Rhodococcus ruber e outros organismos relacionados (Valentin \& Dennis, 1996). Recentemente, Aldor e colaboradores (2002) desenvolveram um sistema de expressão, envolvendo um gene do ciclo de 2-metilcitrato ( $\operatorname{prpC}$ ), associado a genes de formação de propionil-CoA em E. coli ( $s b m$ e $y g f G)$ e genes de biossíntese de PHA de Acinetobacter ( $p h a B C A$ ). O sistema desenvolvido permitiu obter uma linhagem recombinante de Salmonella enterica capaz de produzir $3 \mathrm{HV}$ sem o fornecimento exógeno de propionato. Entretanto, trata-se de produzir propionil-CoA a partir de succinato, que é a via com reações que se processam no sentido inverso às do catabolismo de propionato em humanos e outros eucariotos.

Os trabalhos mais antigos que estudaram o catabolismo de propionato em microrganismos utilizavam ferramentas como a análise de metabólitos após o fornecimento de propionato marcado, ou ainda análise de atividades enzimáticas, que levaram à proposição de diversas vias (London et al., 1999). Em algumas bactérias a atuação simultânea de mais de uma via foi proposta para a sua transformação em acetil-CoA ou succinato (Evans et al., 1993). Diversas vias do catabolismo de propionato em bactérias foram assim propostas (Figura 4) e serão discutidas a seguir.

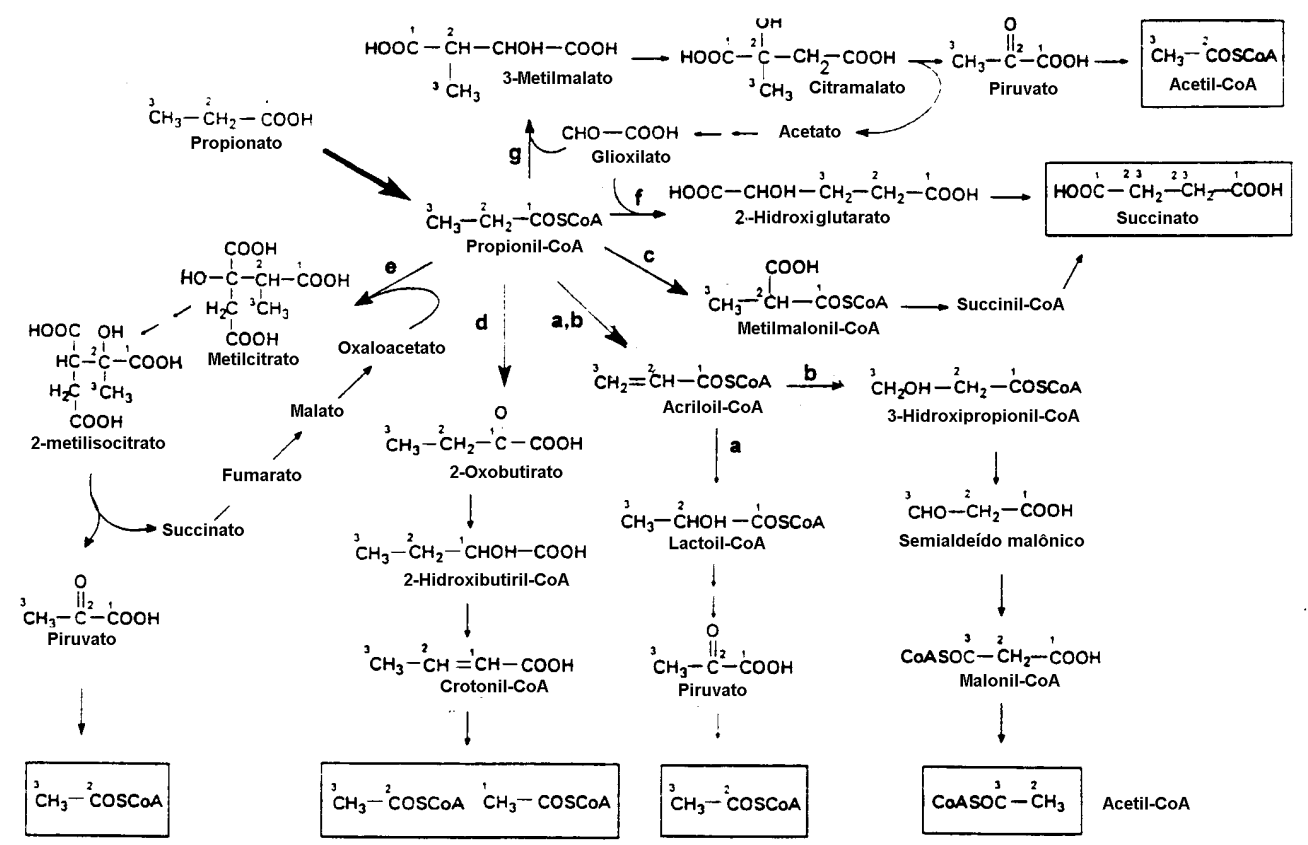

Figura 4. Principais vias descritas para o catabolismo de ácido propiônico (Textor et al., 1997): a) $\alpha$-oxidação, b) $\beta$-oxidação, c) $\alpha$-carboxilação, d) carboxilação redutiva e e-g) condensações de Claisen 
O primeiro passo comum a todas estas vias descritas é a ativação de propionato a propionil-CoA.

\subsubsection{A ativação de propionato a propionil-CoA}

A entrada de propionato na célula foi estudada por Kim e colaboradores (1992) que sugeriram que em Ralstonia eutropha esta se daria na forma de ânion como um antiporte de ânion hidroxi ou na forma não dissociada. A ativação de propionato a propionil-CoA é a primeira etapa proposta para o seu catabolismo por qualquer via. Estudos anteriores, quando não havia evidências da existência de uma propionil-CoA sintetase, atribuíram esta atividade às duas rotas de síntese de acetilCoA (Rhie \& Dennis, 1995 a,b). Em células de Escherichia coli uma dessas rotas é catalisada pela enzima acetil-CoA sintetase (Acs), que tem como intermediário acetiladenilato (AcAMP). A segunda é catalisada pelas enzimas acetato quinase (Ack) e fosfotransacetilase (Pta), passando pelo intermediário acetil fosfato. Acs primeiro converte acetato e ATP para AcAMP produzindo PPi (pirofosfato). AcAMP reage com CoA para formar acetil-CoA e AMP. Similarmente, Ack primeiro converte acetato e ATP para acetil fosfato produzindo ADP, então acetil fosfato reage com CoASH pela Pta para formar acetil-CoA, liberando Pi. Kumari e colaboradores (1995), para comprovar a existência destes genes, clonaram o provável gene acs de $E$. coli, construíram e caracterizaram células de mutantes inativados nestes genes e concluíram que as células de E. coli requerem ambas as vias de ativação de acetato. Foram também publicadas evidências do papel do gene prpE (presente no operon prpBCDE) na síntese de propionil-CoA em Salmonella typhimurium. Quando o gene prpE foi inativado, propionato ainda foi utilizado como fonte de carbono e energia; os mutantes prpE que continham acetil-CoA sintetase (Acs) foram capazes de degradar propionato pelo ciclo de 2-metilcitrato, porém os duplos mutantes prpE acs foram incapazes de degradar propionato pelo $2 \mathrm{MCC}$, indicando que Acs poderia compensar a falta de propionil-CoA sintetase para a degradação de propionato em mutantes prpE (Horswill e Escalante-Semerena, 1999).

Horswill e Escalante-Semerena (2002) propuseram que prpE atua na primeira rota de ativação de ácidos graxos em Salmonella enterica e ocorre em dois passos, o primeiro passo através de acil-CoA sintetase ativador de grupos acil que catalisa 
reações através dos intermediários adenilatos chamados acil-adenilato/tioésteres e o segundo passo através do intermediário acil-adenilato (acil-AMP).

Recentemente, Palacios e colaboradores (2003) propuseram que Salmonela enterica produz uma propionil-CoA sintetase que é parte do produto de expressão do operon $\operatorname{prp} B C D E$, sob controle do gene $\operatorname{prpR}$, regulador transcricional que necessita de 2 metilcitrato como ativador. A síntese de 2-metilcitrato pelo gene prpC necessita de propionil-CoA como substrato, porém o nível de propionil-CoA necessita ser aumentado através de Acs ou sistema PduW-Pta (propionato kinasefosfotransacetilase) antes que a 2-metilcitrato possa ser sintetizada e a transcrição de prpBCDE possa ser ativada. Os autores também observaram que outro gene $\operatorname{cob} B$, que pode usar propionato, bem como 1,2-propanodiol como fonte de carbono e energia, faz com que seja expresso o operon $\operatorname{prp} B C D E$ pela proteína Pdu que tem atividade com o gene cobB (Tsang et al., 1996, 1998). Este gene também é necessário para a interação da via requerida para degradação de propionato e 1,2 propanodiol (utiliza o operon pdu), pois $c o b \mathrm{~B}$ tem a função de desacetilase que é requerida para a ativação de acetato a acetil-CoA e propionato a propionil-CoA. A acetilação é uma característica no controle pós traducional dos membros das atividades bioquímicas da AMP, cuja falta bloqueia a síntese de ácidos graxos de cadeia curta (Starai et al., 2002, 2003) e que PduW é importante para a síntese de popionil-CoA no crescimento em 1,2-propanodiol que é precursor da via 2 metilcitrato. Concluiu-se que o catabolismo do ciclo de 2-metilcitrato (2MCC) requer sistema PduW-Pta, acetil-CoA (Acs) e propionil-CoA (prpE).

Porém, este gene prpE presente em Salmonella typhimurium não está presente no operon prpBCD de outros organismos como: Ralstonia eutropha HF39 e Burkholderia sacchari (Brämer e Steinbüchel, 2001, Brämer et al., 2002).

\subsubsection{O destino de propionil-CoA}

Uma vez ativado a propionil-CoA, vários destinos foram propostos na literatura para o seu catabolismo (Figura 4).

Reeves e colaboradores (1963) faziam parte de um dos primeiros grupos a propor a via de $\alpha$-hidroxiglutarato para o catabolismo de propionato: $\alpha$ hidroxiglutarato é um produto da $\beta$-condensação enzimática entre glioxilato e 
propionil-CoA, formando $\beta$-metilmalonato, que passa por uma isomerização e forma $\alpha$-hidroxiglutarato (Figura 4f). Esta via também foi identificada em E. coli K12 na qual apenas após a mutação da bactéria esta passou a crescer em propionato e necessitava da via de hidroxiglutarato em altos níveis (Kay, 1972).

Por um longo tempo, acreditou-se que o catabolismo de ácido propiônico em E. coli ocorria principalmente pela $\alpha$-oxidação via lactato (Figura $4 \mathrm{a}, \mathrm{b}$ ) (Wegener et al., 1968, Sprat et al., 1981).

Evans e colaboradores (1993), bem como outros autores, consideraram que a via melhor estabelecida até então era a que promove a $\alpha$-carboxilação de propionilCoA a metilmalonil-CoA (Figura 4c) que levaria à formação de succinil-CoA que entraria no ciclo dos ácidos tricarboxílicos (TCA), estando distribuída entre bactérias aeróbias e anaeróbias, bem como mitocôndrias de humanos e de animais. Os autores consideravam também que, em presença de vitamina B12, E. coli também se utilizaria desta via para o consumo de propionato (Evans et al., 1993). Porém a proposta de funcionamento da via do metilmalonil-CoA foi unicamente baseada em experimentos nos quais se observava um aumento do consumo do propionato ou uma redução na fase lag, quando o meio era suplementado com vitamina B12 ou bicarbonato. Estudos mais recentes, utilizando propionato marcado em duas posições, demonstraram que não é necessário invocar a via do metilmalonil-CoA ou $\alpha$-hidroxiglutarato para explicar o metabolismo de propionato em E. coli (London et al., 1999). London e colaboradores (1999) forneceram propionato $1,2-{ }^{13} \mathrm{C}_{2}$ para análise do metabolismo de ácido propiônico, para distinguir entre as vias do metilcitrato e metilmalonato. A preservação do esqueleto carbônico ${ }^{13} \mathrm{C}-{ }^{13} \mathrm{C}-{ }^{12} \mathrm{C}$ em alanina marcada e alanina contendo peptídeos envolvidos na parede celular foram indicativos da formação direta de piruvato a partir do propionato via ciclo de metilcitrato (Figura 4e). Ainda assim, alguns autores têm perseguido a comprovação da presença da via de metilmalonilCoA dependente de vitamina B12 em E. coli, estudando mutantes afetados na síntese de vitamina B12 (Araújo et al., 2004).

Em uma outra via, proposta a partir de estudos com metanogênicos, propionilCoA sofreria uma carboxilação redutiva a 2-oxobutirato (Figura 4 d) que, por sua vez, seria reduzido a 2-hidroxibutiril-CoA e desidratado na posição $\alpha$ gerando crotonilCoA. Este sofreria $\beta$-oxidação, formando acetil-CoA (Tholozan et al., 1990; Textor et al., 1997). 


\subsubsection{Estudos buscando evidências genéticas para presença de vias catabólicas}

Embora diversas vias tenham sido propostas para o metabolismo de propionato, sua confirmação ainda necessita de evidências genéticas. Sprat e colaboradores (1981) relatam a presença de um gene que afeta o metabolismo de propionato, localizado a aproximadamente 98 minutos no cromossomo de E. coli. No mapa de ligação de E. coli K12, este gene foi denominado prpA (Berlyn, 1998). Entretanto, apesar do seqüenciamento de todo o genoma de E. coli (Kroeger \& Wahl, 1997), nenhuma relação clara entre o gene prpA e uma via específica do catabolismo de propionato foi estabelecida na década passada (Textor et al., 1997) e ainda hoje. Apenas para o ciclo de 2-metilcitrato, inicialmente descrito em fungos e leveduras

(Tabuchi et al., 1974; Tabuchi \& Uchyiama, 1975; Pronk et al., 1994) e, posteriormente, em bactérias (Gerike et al., 1998, Horswill e Escalante-Semerena, 1997, Textor et al., 1997, Silva, 1998, Brämer \& Steinbüchel, 2001, Brämer et al., 2002), as bases genéticas estão bem estabelecidas. Nestas bactérias, os genes do 2MCC estão organizados em um operon prpBCD .

A via metabólica que condensa oxaloacetato com propionato formando 2metilcitrato foi descoberta em Candida lipolytica (Tabuchi \& Uchyiama, 1975). A atividade de enzimas desta via foi medida em Saccharomyces cerevisiae (Pronk et al., 1994). Nesta via, o propionato é oxidado a piruvato via 2-metilcitrato. As funções codificadas pelo operon prpBCD são necessárias para catalisar as reações nesta via. Inicialmente, propionato é ativado a propionil-CoA pela ação de uma propionil-CoA sintetase (codificada pelo gene prpE) (que nem sempre está presente no operon). Em seguida, propionil-CoA é condensada com oxaloacetato, pela ação da enzima 2metilcitrato sintase (codificada pelo gene $\operatorname{prpC}$ ), sendo formado 2-metilcitrato. A clivagem de 2-metilisocitrato em piruvato e succinato é catalisada pela enzima 2metilisocitrato liase (codificada por prpB). Em 1997, Horswill e Escalante-Semerena caracterizaram os genes do operon prp em Salmonella typhimurium LT2, demonstraram a seqüência de nucleotídeos de duas unidades transcricionais, uma unidade que compreende o gene $\operatorname{prp} R$ que codifica ativadores da família sigma-54 e a outra unidade contém o operon de quatro genes denominados $\operatorname{prp} B, \operatorname{prp} C, \operatorname{prpD}$, prpE, (operon prpBCDE). Os autores demonstraram o envolvimento destes genes no catabolismo de propionato pela análise de complementação de mutantes. 
Ainda em 1997, estudos com ressonância nuclear magnética (NMR) em Escherichia coli cultivada em propionato evidenciaram, pela primeira vez, que este substrato também é oxidado a piruvato pelo 2MCC (Textor et al., 1997). Estes autores deduziram a existência desta via, a partir do crescimento bacteriano utilizando propionato marcado radioativamente $\left(2-{ }^{13} \mathrm{C}, 3-{ }^{13} \mathrm{C}\right.$ ou $\left.{ }^{3} \mathrm{H}_{2}\right)$, pois verificaram que o propionato foi oxidado a piruvato sem randomização do esqueleto carbônico, permitindo excluir as vias nas quais o grupo metil é transitoriamente convertido para o grupo metileno. Os autores (Textor et al., 1997) analisaram extratos de células crescidas em propionato e estes continham enzimas específicas que catalisavam a condensação de propionil-CoA com oxaloacetato, mais provavelmente pelo ciclo de 2 metilcitrato. Esta enzima foi purificada e identificada como citrato sintase II (hoje conhecida como 2 metilcitrato sintase). Além disso, foi identificada uma segunda enzima por eletroforese em gel bidimensional com seqüência similar para isocitrato liase. Os genes de ambas as enzimas foram localizados em um provável operon com alta similaridade com o operon de Salmonella typhimurium. Gerike e colaboradores (1998) comprovaram a existência do $2 \mathrm{MCC}$ em E. coli, propondo que a 2 metilcitrato sintase seria induzida durante crescimento em propionato e que este seria convertido a succinato e piruvato. A seqüência de aminoácidos correspondentes apresentou $96 \%$ de homologia com uma possível citrato sintase de S. typhimurium ( $\operatorname{rpC}$ ), envolvida no consumo de propionato, mas apenas 30\% de homologia com a citrato sintase hexamérica de E. coli $(g l t \mathrm{~A})$, envolvida no TCA. Os autores avaliaram então a atividade das duas citrato sintases de E. coli, uma dimérica e outra hexamérica, utilizando acetil-CoA e propionil-CoA como substratos, para a condensação com oxaloacetato. Os resultados indicaram que a "segunda" citrato sintase é uma 2metilcitrato sintase (2MCS), ao contrário da enzima hexamérica, que não possui atividade com propionil-CoA. (Gerike et al., 1998).

Mais recentemente, esta via foi descrita em Ralstonia eutropha HF 39 (Brämer e Steinbüchel, 2001), pelo estudo de mutantes produzidos por recombinação homóloga que foram afetados no crescimento em propionato. Estes mutantes foram analisados sob os aspectos molecular, fisiológico e enzimático. Os autores caracterizaram genes envolvidos no catabolismo de propionato nesta bactéria e demonstraram que estes genes estavam organizados em um operon prp onde se apresentaram na seguinte ordem $\operatorname{prpR}, \operatorname{prpB}, \operatorname{prp} C, A c n M$, ORF5 prpD. A ação dos produtos dos genes $\operatorname{prp} C$ e $\operatorname{prp} B$ foi comprovada por medida de atividade enzimática 
e o produto do gene $\operatorname{prpB}$ também foi comprovado através do acúmulo de 2metilisocitrato no sobrenadante de mutantes $\operatorname{prpB}$. O gene acnM codifica uma enzima com função de 2-metil-cis-aconitato hidratase, e $\operatorname{prpD}$ codifica uma 2metil-cisaconitato desidratase diferente do gene prpD da Salmonella enterica. O produto de $\operatorname{prpR}$ é um provável regulador transcricional com similaridade a família sigma-54. O locus prp em $R$. eutropha apresentou-se muito diferente do locus de E. coli e $S$. enterica.

O passo desta via que foi mais difícil de esclarecer é a conversão de 2metilcitrato a 2-metilisocitrato. Foi descoberto o possível papel da proteína $\operatorname{PrpD}$ no catabolismo de propionato em Samonella enterica (Horswill \& Escalante-Semerena, 2001) até então desconhecido. Os autores mostraram que a proteína PrpD está envolvida na reação de conversão de 2-metilcitrato para 2-metilisocitrato, sugerindo que $\operatorname{PrpD}$ pode ser uma aconitase diferente da aconitase que converte citrato para isocitrato, ou uma nova enzima que catalisa a desidratação de 2-metilcitrato para 2metil-cis-aconitato, ou ainda hidratação de 2-metil-cis-aconitato para 2metilisocitrato. Horswill e Escalante-Semerena (2001) demonstraram que a proteína $\operatorname{PrpD}$ desidrata 2-metilcitrato para 2-metil-cis-aconitato, mas não converte o último para 2-metilisocitrato, portanto, $\operatorname{PrpD}$ não tem atividade aconitase. Com base nestes resultados, foi proposto o metabolismo de propionato pelo ciclo de 2-metilcitrato conforme apresentado na Figura 5.

Blank e colaboradores (2002) caracterizaram o gene codificador da 2metilcitrato desidratase (prpD), localizado no operon prp $B C D$ de E. coli, que é diretamente relacionado com o operon equivalente de $S$. typhimurium, já extensivamente estudado por Horswill e Escalante-Semerena (1997, 1999, 2001). 


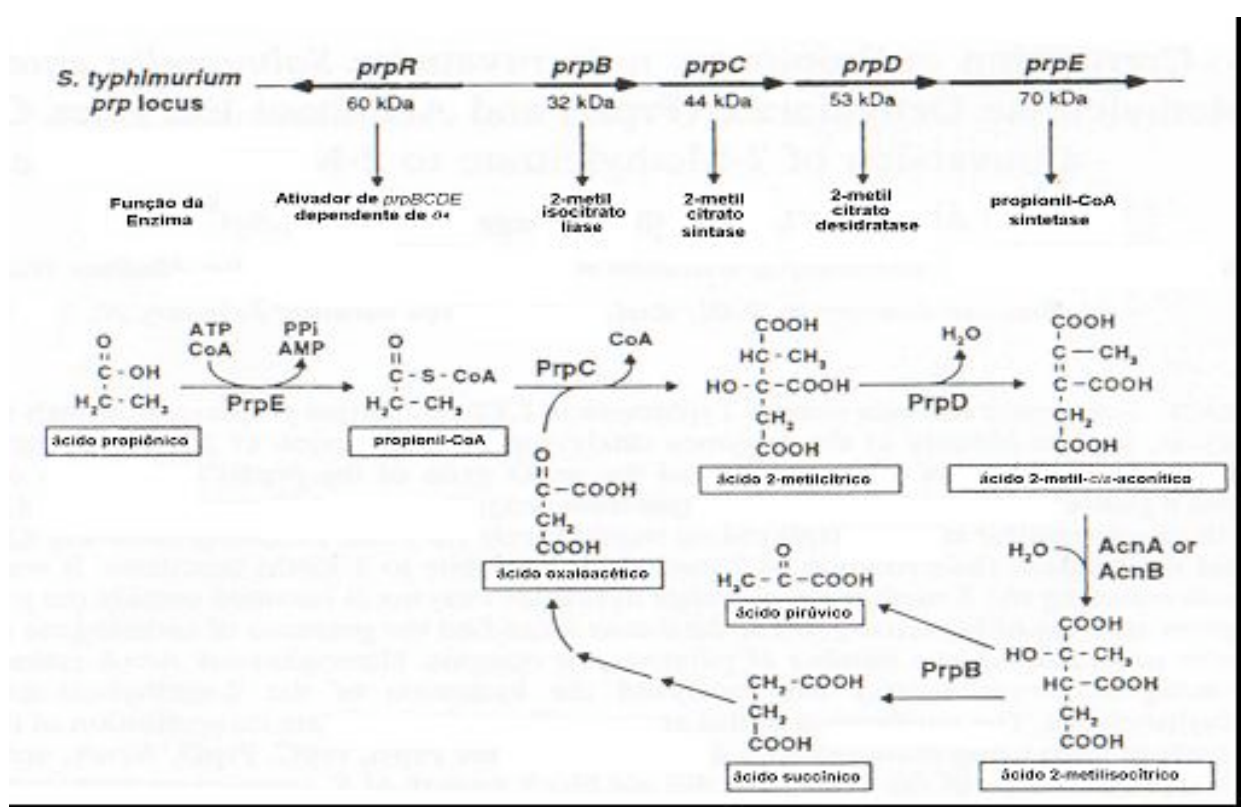

Figura 5. Catabolismo de propionato em Salmonella typhimurium (Horswill e Escalante-Semerena, 2001).

Blank e colaboradores (2002) caracterizaram duas aconitases AcnA e AcnB e uma menor atividade AcnC que é conservada pelo duplo mutante acn $A B$ e representa não mais que $5 \%$ do total da atividade de aconitase na linhagem selvagem. Estes autores demonstraram que a 2-metilcitrato desidratase codificada pelo gene $\operatorname{prp} D$ do catabolismo de propionato é idêntica a $a c n C$. Baseados em seus trabalhos e de outros autores, propuseram as reações apresentadas na figura 6 para o catabolismo de propionato pelo ciclo de 2-metilcitrato (Figura 6).

$\begin{array}{ll}\text { Propionato }+\mathrm{CoA}+\mathrm{ATP} \rightarrow \text { Propionil-CoA }+\mathrm{ADP} / \mathrm{AMP} & \text { prpE } \\ \text { Propionil-CoA }+ \text { Oxaloacetato } \rightarrow \text { 2-Metilcitrato } & \text { prpC } \\ \text { 2-Metilcitrato } \rightarrow \text { 2-Metilcis-aconitato }+\mathrm{H}_{2} \mathrm{O} & \text { prpD } \\ \text { 2-metilcis-aconitato }+\mathrm{H}_{2} \mathrm{O} \rightarrow \text { 2-Metilisocitrato } & ? \\ \text { 2-Metilisocitrato } \rightarrow \text { Piruvato }+ \text { succinato } & \text { prpB } \\ \text { Succinato }+\mathrm{FAD}+\mathrm{NAD} \rightarrow \text { Oxaloacetato }+\mathrm{FADH}_{2}+\mathrm{NADH}^{+} & \mathrm{CAC}^{*} \\ \text { Propionato }+\mathrm{ATP}+\mathrm{FAD}+\mathrm{NAD} \rightarrow \text { Piruvato }+\mathrm{ADP} / \mathrm{AMP}+\mathrm{FADH}_{2}+\mathrm{NADH}^{+}\end{array}$

Figura 6. Reações do ciclo de 2-metilcitrato (2MCC) para o catabolismo de propionato em $S$. typhimurium. *enzimas do ciclo do ácido cítrico.

Brock e colaboradores (2002) também estudaram a isomerização de $2 S, 3 S$ metilcitrato para $2 R, 3 S$-2-metilisocitrato em $E$. coli e que esta requer metilcitrato desidratase $(\operatorname{PrpD})$ e aconitase $(\mathrm{AcnB})$ do ciclo dos ácidos tricarboxílicos, sendo 
$\operatorname{PrpD}$ específica para 2S,3S-metilcitrato e o produto da desidratação de $2 S, 3 S$ metilcitrato foi designado cis-2metilaconitato. $\mathrm{O}$ gene $\operatorname{prpD}$ codifica uma proteína que catalisa uma syn eliminação não usual e a hidratação de cis-2metilaconitato ocorre de maneira anti. A diferente estequiometria de eliminação e adição de água pode ser a razão para o requerimento do produto do novo gene $\operatorname{prpD}$ (metilcitrato desidratase), mas este não catalisa a hidratação de cis-2metilaconitato para $2 R, 3 S$-2metilisocitrato. Em Salmonella entérica, os produtos de acnA e $a c n B$ catalisam esta hidratação. Foi então proposto que o produto de $a c n B$ tem duas funções em E. coli: a catálise de metilisocitrato desidratase e uma citrato/isocitrato isomerização do TCA. A eliminação syn de água não é usual e, devido a isso, o gene $\operatorname{prpD}$ não tem muita similaridade com genes de outras bactérias e explica porque a conversão de $2 S, 3 S$ metilcitrato para $2 R, 3 S$-2metilisocitrato não pode ser catalisada só por aconitase.

Grimek e co-autores (2003) publicaram um estudo da atividade do produto do gene $\operatorname{prpB}$ (2 metilisocitrato liase) de E. coli e mostraram que dois resíduos (C123 e D58) localizados no sítio ativo desta enzima são essenciais para a conversão de metilisocitrato para piruvato e succinato, cujo mecanismo é similar ao da isocitrato liase (TCA) e que apresentam atividade semelhante à do produto da expressão do gene $\operatorname{prp} B$ de $S$. enterica.

Recentemente foi estudada a função da proteína PrpR de Salmonella enterica serovar typhimurium LT2. PrpR funciona como um sensor de 2-metilcitrato (2-MC) que é um intermediário do $2 \mathrm{MCC}$. Neste trabalho, os autores mediram a atividade de PrpR na presença de citrato e propionato, porém PrpR não apresentou resposta em relação a nenhum deles, tendo apresentado atividade na presença de $2 \mathrm{MC}$, concluindo que $2 \mathrm{MC}$ e não o propionato é o metabolito que sinaliza a presença de propionato em Salmonella enterica serovar typhimurium LT2. Foram medidas também as atividades de várias proteínas mutadas codificadas por prpR com vários níveis de $2 \mathrm{MC}-$ independente e foi demonstrado que a ativação transcricional do operon prpBCDE e promotores prpR requerem a função do fator sigma 54 PrpR e IHF (Palacios e Escalante-Semerena, 2004). Demonstraram que a transcrição de prpBCDE e promotores $\operatorname{prp} R$ foram 'down-reguladas' por adição de glicose e glicerol indicando que estes genes poderiam ser regulados pelo complexo cAMP receptor protein" (CRP-cAMP), que é um dímero de subunidades idênticas que se ligam em DNAs específicos ou não. $\mathrm{O}$ alvo da mutagênese de um provável sítio de ligação CRP na região promotora entre $\operatorname{prpR}$ e $\operatorname{prp} B C D E$ sugere que estes genes estão sob o controle 
de CRP. Concluíram que o metabolismo de propionato é sujeito à repressão catabólica por regulador transcricional CRP global e que este regulador é afetado por genes reguladores de $\operatorname{prpR}$ e $\operatorname{prp} B C D E$. A regulação destes dois promotores divergentes poderia ter importantes implicações no mecanismo de repressão catabólica CRPdependente em conjunto com o membro da família de ativadores transcricionais sigma-54 (Lee et al., 2005).

Grimek e Escalante-Semerena (2004) mostraram que Shewenella oneidensis e Vibrio cholerae possuem dois genes $\mathrm{prpF}$ e $a c n D$ que quando expressos compensam a falta da enzima $\operatorname{PrpD}$ Fe/S -independente em mutantes de Salmonella enterica durante crescimento em propionato. A proteína AcnD de Shewenella oneidensis isolada mostrou ter uma nova atividade para a enzima contendo $\mathrm{Fe} / \mathrm{S}$. A proteína AcnD catalisa a desidratação de $2 \mathrm{MC}$ e citrato mas não catalisa a desidratação de $2 \mathrm{MIC}$ ou isocitrato. Espectroscopia ${ }^{13} \mathrm{C}-\mathrm{NMR}$ revelou que $\left[2-{ }^{13} \mathrm{C}\right] \mathrm{MC}$ poderia utilizar 2MC gerado pela enzima PrpC de Salmonella enterica e que o produto de reação AcnD coincidiu com o produzido por PrpD em Salmonella enterica (2MCA). PrpF pode ser uma isomerase de um intermediário do $2 \mathrm{MCC}$, sendo improvável que PrpF seja um 2MIC isomerase porque o gene $\operatorname{prpB}$ de Shewenella oneidensis complementou um mutante $\operatorname{prpB}$ de Salmonella enterica, e dados de NMR sugerem que o gene $a c n D$ somente catalisa a conversão de $(2 S-3 S)$-MC para $2 \mathrm{MCA}$. Seria também possível que PrpF fosse uma $2 \mathrm{MC}$ isomerase. Porém dados mostraram que a proteína PrpC de Shewenella oneidensis gerou o mesmo estereoisômero de 2-MC como que gerou o $\operatorname{PrpC}$ de $S$. enterica. Os autores consideraram improvável que a enzima PrpD de S. enterica utilize 2EMC como substrato. PrpF pode estar envolvido na formação ou reparo do cluster AcnD Fe/S, acompanhando AcnD para compensar a falta da enzima $\operatorname{PrpD}$ durante crescimento em propionato em mutantes de $S$. enterica.

Claes e colaboradores (2002) publicaram que Corynebacterium glutamicum possui dois genes homólogos codificadores para citrato sintase (glta) que se apresentam em dois operons prpDBC (prpD1B1C1 e prpD2B2C2), prpC1 e prpC2 . Os produtos de ambos são ativos como citrato sintase e 2-metilcitrato sintase, porém análise mutacional revelou que apenas prpD2B2C2 é essencial para crescimento desta bactéria em propionato como fonte de carbono e energia e que a função de prpD1B1C1 apresenta-se obscura. Este é o primeiro trabalho publicado em que o $2 \mathrm{MCC}$ é descrito em bactérias gram positivas e que apresenta a característica de ter duas cópias cromossomais dos genes prp. Algumas bactérias gram positivas como 
Bacillus subtilis, Bacillus halodurans apresentam operon prpCDB, porém não há nenhuma análise funcional dos genes prp, quanto a evidência bioquímica do 2MCC.

Um estudo recentemente publicado pretende trazer subsídios para determinar o papel do 2MCC no metabolismo, crescimento intracelular e virulência de Mycobacterium tuberculosis (Muñoz-Elias et al., 2006). Este microrganismo possui homólogos de metilcitrato sintase e metilcitrato desidratase, mas não de 2metilisocitrato liase. Embora a 2-metilisocitrato liase tenha uma limitada homologia com isocitrato liases do ciclo do glioxilato, acredita-se que estas enzimas não sejam funcionalmente sobrepostas. Muñoz-Elias e colaboradores (2006) apresentaram evidências de que as isoformas 1 e 2 de 2-metilisocitrato liase são conjuntamente necessárias para o crescimento em ácidos graxos, em macrófagos e em camundongos e ainda que ambas as isoformas atuam como isocitrato liase no ciclo do glioxilato e como 2-metilisocitrato liase no 2MCC.

\subsubsection{O catabolismo de propionato em Burkholderia sacchari}

O uso de propionato para a produção de PHA vem sendo estudado em $B$. sacchari IPT/LFM 101, tendo-se demonstrado que, de modo similar a outras bactérias, a conversão de propionato em unidades $3 \mathrm{HV}$ é restrita a menos que $10 \%$ do máximo teórico (Silva et al., 2000; Brämer et al., 2001). Mutantes de B. sacchari, incapazes de crescer em propionato ( $p r p$ ), mas que acumulam unidades $3 \mathrm{HV}$ a partir deste substrato, foram obtidos, classificados e comparados, buscando-se melhorar o rendimento obtido (Silva et al., 2000). Foram definidos dois grupos de mutantes UV: um afetado na utilização de intermediários da $\alpha$-oxidação e outro não afetado. Enquanto o valor do fator de conversão de propionato a unidades $3 \mathrm{HV}$, apresentada pela linhagem selvagem, era $\mathrm{Y}_{3 \mathrm{HV} / \mathrm{Prop}}=0,10 \mathrm{~g} / \mathrm{g}$, mutantes do primeiro grupo atingiam, no máximo $\mathrm{Y}_{3 \mathrm{HV} / \mathrm{Prop}}=0,37 \mathrm{~g} / \mathrm{g}$, ao passo que mutantes não afetados nesta via atingiam até $0,80 \mathrm{~g} / \mathrm{g}$. A soma destes valores corresponde a $1,17 \mathrm{~g} / \mathrm{g}$, bastante próximo do rendimento máximo teórico de $1,35 \mathrm{~g} / \mathrm{g}$. Foi proposto então que o ácido propiônico seria consumido por pelo menos três vias: duas vias de degradação (cada uma bloqueada em cada grupo de mutantes), as quais competiriam ainda com uma terceira via, a de síntese de 3HV (Figura 7). 

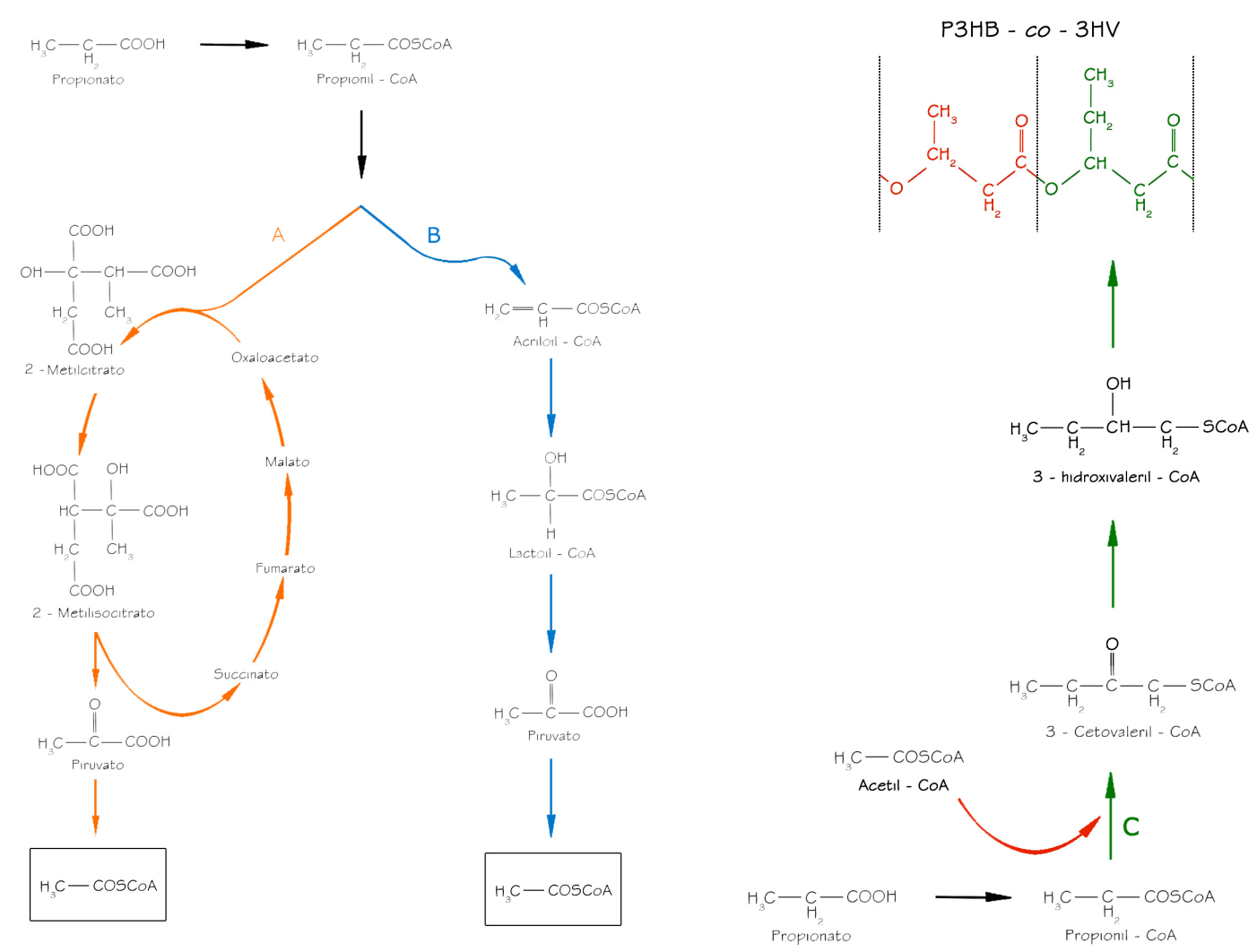

Figura 7a. Esquema das vias do Figura 7b. Via de produção de unidades catabolismo de propionato propostas: 2MCC e $\alpha$ $\mathrm{HV}$, que compete com as duas vias do catabolismo da oxidação bactéria.

\subsubsection{Ciclo do 2-Metilcitrato em B. sacchari}

O 2MCC foi definido em B. sacchari a partir da clonagem de um fragmento genômico E2 $(2 \mathrm{~Kb})$ a partir do qual foi subclonado um fragmento Sal $1 \mathrm{de} 1.1 \mathrm{~Kb}$ (S1), capaz de restituir o fenótipo prp ao mutante IPT/LFM 189 (Silva, 1998) (Figura 8). Este fragmento foi seqüenciado e identificado como codificador de parte do gene $\operatorname{prpC}$ e parte de $a c n M$, capaz de restituir o fenótipo prp+ ao mutante IPT/LFM 189 (Silva, 1998). No entanto, S1 não foi capaz de complementar outros quatro (IPT/LFM 192, 193, 195 e 196) dos mutantes do mesmo grupo de IPT/LFM 189 (não afetados na $\alpha$-oxidação e com capacidade de conversão de propionato a $3 \mathrm{HV}$ aumentada de 0,10 para 0,80 g/g), complementando apenas IPT/LFM 197, além de IPT/LFM 189. Isto pode indicar que outras regiões do genoma, quando afetadas, também interferem significativamente na síntese de polímero. Tais mutantes poderiam estar afetados em 
outras regiões do mesmo operon ou não, igualmente relevantes para drenar propionato da síntese de polímero.
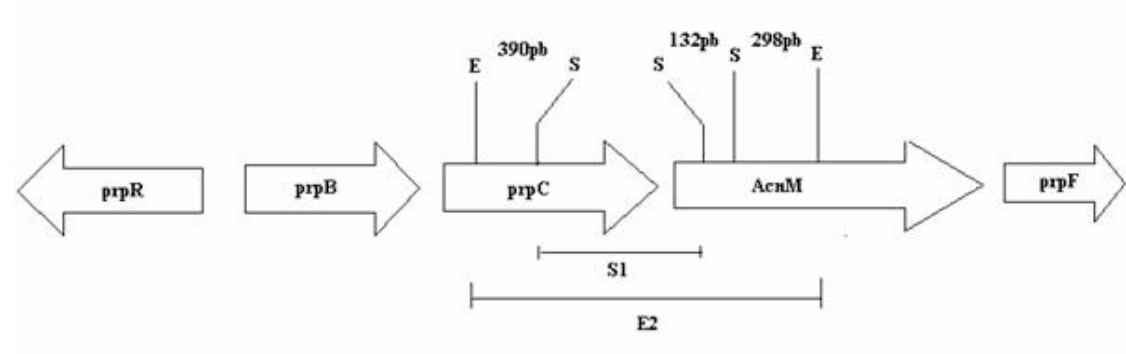

Figura 8. Operon prp de Burkholderia sacchari (Silva, 1998)

A partir de resultados do seqüenciamento de $\mathrm{S} 1$ e regiões adjacentes, Brämer e co-autores (2002) demonstraram, do ponto de vista molecular, a presença do $2 \mathrm{MCC}$ em B. sacchari . O operon prp descrito é composto de quatro genes ( $p r p B, p r p C$, acnM e a open reading frame-ORF5) que mostram identidade com genes dos loci prp de muitas bactérias. O gene $\operatorname{prpC}$ codifica a 2-metilcitrato $\operatorname{sintase}$, $\operatorname{prpB}$ codifica a 2metilisocitrato liase, e os genes $a c n M$ e ORF5 provavelmente são requeridos para a conversão de ácido 2-metilcítrico em ácido 2-metilisocítrico. Um outro gene (prpR) posicionado à montante do operon, com uma orientação invertida, codifica um provável regulador transcricional do operon prp. Três ORFs adicionais $(6,7,8)$, cujas funções são desconhecidas, foram localizados à jusante a ORF5 no locus prp de $B$. sacchari e não foram encontradas em nenhum outro operon. O gene prpD, provavelmente envolvido na reação de isomerização no $2 \mathrm{MCC}$ em $S$. enterica, não foi localizado no locus prp de B. sacchari. Se, em B. sacchari, os produtos dos genes acnM e ORF 5 estiverem também envolvidos na conversão de 2-metilcitrato a 2 metilisocitrato, como ocorre em R. eutropha HFR39 (Brämer \& Steinbüchel, 2001), os autores inferem que o produto do gene $\operatorname{prpD}$ não é requerido para a funcionalidade deste ciclo nesta bactéria. Considerando que os produtos das ORFs 6, 7, 8 podem não ser necessários para a funcionalidade da 2-metilcitrato sintase em B. sacchari, foi proposto um conjunto mínimo de genes estruturais para o locus prp desta linhagem, responsáveis pela funcionalidade do ciclo de 2-metilcitrato.

A identificação do $2 \mathrm{MCC}$ em $B$. sacchari permitiu a construção de mutantes especificamente inativados em $\operatorname{prp} C$ e $a c n M$, que ainda assim não alcançaram o valor máximo teórico de $\mathrm{Y}_{3 \mathrm{HV} / \text { prop }}$ (Pereira et al., 2001, Pereira, 2002, Pereira et al., 2005, 
Pereira, 2007). Este e outros resultados de Pereira (2007) corroboram a presença de mais de uma via no catabolismo de propionato em B. sacchari.

É de interesse o conhecimento detalhado da relevância de cada gene do $2 \mathrm{MCC}$ e seu emprego a obtenção de mutantes que mais se aproximem do valor máximo teórico de $\mathrm{Y}_{3 \mathrm{HV} / \text { Prop }}=1,35 \mathrm{~g} / \mathrm{g}$ apenas pela modificação genética. A identificação dos genes codificados pelas regiões afetadas nestes mutantes trará também importante contribuição sobre o papel destes genes, sejam eles do $2 \mathrm{MCC}$ ou não, sobre a síntese de unidades $3 \mathrm{HV}$, trazendo à luz novos aspectos do catabolismo de propionato nesta bactéria e indicando de que modo o bloqueio ou redirecionamento das vias envolvidas afetarão a síntese de $3 \mathrm{HV}$.

\subsubsection{Alfa-oxidação}

Os passos envolvidos em uma $\alpha$-oxidação de propionato estão esquematizadas na figura 9.

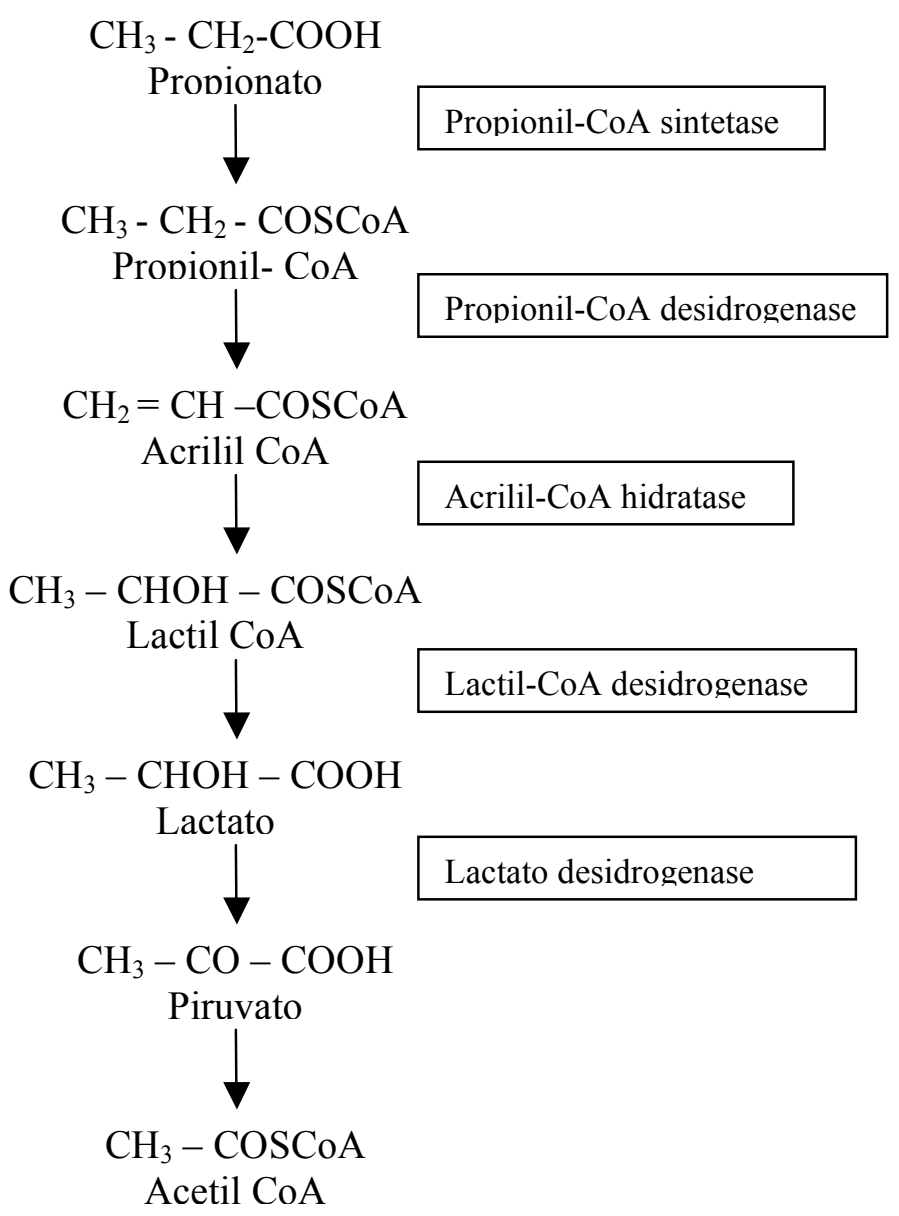

Figura 9. Via da $\alpha$-oxidação de propionato, mostrando as enzimas envolvidas nesta via. 
A oxidação de propionato por esta via foi proposta para E. coli em 1968 por Wegener e colaboradores. Em 1988 e 1989, Fernandez-Briera e Garrido-Pertierra, por meio de estudos com S. Typhimurium, publicaram trabalhos que corroboram a hipótese da existência desta via. Em 1993, Evans e colaboradores sugeriram que propionato seria carboxilado a succinato ou oxidado a piruvato, sem no entanto indicar se última ocorreria por $\alpha$-oxidação. Todos estes trabalhos se basearam em cultivos de bactérias em propionato marcado e análise dos metabólitos gerados, bem como na medida de atividade de diversas enzimas, que pode levar a resultados enganoso, como posteriormente comentado (London et al., 1999).

Sprat e colaboradores (1981) locarizaram um locus, denominado prpA, em $S$. Typhimurium correlacionado à quebra de propionato que, entretanto não foi caracterizado no nível molecular. 


\section{CONCLUSÕES}

- O sistema de empacotamento de DNA em capsídeo do fago $\lambda$, obtido neste trabalho, mostrou-se eficiente, tanto no reconhecimento do próprio DNA $\lambda$, como de fragmentos de DNA bacteriano, ligados ao cosmídio pVK100, e ainda na sua transdução para $E$. coli $\mathrm{S} 17-1$;

- Com o sistema de empacotamento obtido, foi construída uma biblioteca genômica de B. sacchari, representativa do genoma desta bactéria, constituída de mais de 4000 clones;

- Mutantes de B. sacchari, mais eficientes na conversão de propionato a unidades $3 \mathrm{HV}$, incapazes de crescer em propionato como única fonte de carbono (prp) e, ainda afetados no uso de intermediários da $\alpha$-oxidação de propionato, foram reclassificados fenotipicamente, tendo sido observado que o uso de um dos intermediários (acrilato) depende da concentração fornecida;

- Experimentos de complementação de alguns mutantes frente a todos os clones de bibliotecas genômicas de B. sacchari construídas revelaram que três deles $\left(\mathrm{A}_{1}, \mathrm{P}_{1}\right.$ e $\left.\mathrm{P}_{2}\right)$ restituíam a capacidade crescimento em propionato a estes mutantes. Entretanto, avaliação quantitativa de um destes clones $\left(\mathrm{A}_{1}\right)$ mostrou que esta complementação era apenas parcial, ou seja restituía apenas parcialmente a eficiência original da linhagem selvagem em converter propionato a unidades $3 \mathrm{HV}$;

- $\quad \mathrm{P}_{1}$ foi capaz de restituir a capacidade de de crescimento em propionato, bem como em outros intermediários da $\alpha$-oxidação a um dos mutantes avaliados. A partir de subclonagens de $\mathrm{P}_{1}$, foi obtido um fragmento menor, de cerca de 1,2 $\mathrm{Kb}\left(\mathrm{T}_{6}\right)$, ligado ao plasmídio pBBR1MCS2, ainda capaz de restituir a capacidade de crescimento em propionato a dois dos mutantes estudados; 
- Análise da seqüência de aminoácidos codificada pelo fragmento de DNA $\mathrm{T}_{6}$, revelou similaridade com seqüências de reguladores transcricionais do tipo LysR (LTTRs) de diversas bactérias, inclusive do gênero Burkholderia;

- Uma busca pelas regiões adjacentes aos genes codificadores de LysR em diversas espécies de Burkholderia mostrou a presença de genes codificadores de: acil-CoA desidrogenase, uma possível acil-CoA transferase/L-carnitina desidratase (Predicted acyl-CoA transferases/carnitine dehydratase) e uma permease da superfamília de facilitadores MFS-1, enzimas que podem estar envolvidas na $\alpha$-oxidação de propionato. 


\section{REFERÊNCIAS BIBLIOGRÁFICAS}

Aldor IS, Kim SW, Prather KLJ, Keasling JD. Metabolic engineering of a novelpropionate-independent pathway for the production of poly(3-hydroxybutyrate-co3hydroxyvalerate) in recombinant Salmonella enterica serovar Thyphimurium. Appl Environ Microbiol. 2002; 68(8): 3848-3854.

Anderson AJ, Dawes EA. Occurrence, metabolism, metabolic role, and industrial uses of bacterial polyhydroxyalkanoates. Microbiol Rev. 1990; 54: 450-472.

Araújo DG, Pitlovanciv AK, Antonio RV. Inativação do gene BIRA de Escherichia coli recombinantes e seu efeito sobre a produção de polihidroxialcanoatos. Em: Florianópolis; 2004. CD-ROM de Resumos. Ribeirão Preto: Sociedade Brasileira de Genética; 2004. GM 076.

Ausubel E, Brent R, Kingston RE, Moore DD, Seidman JG, Smith JA, Stuhl K. Current protocols in molecular biology. New York: John Wiley \& Sons; 1992.

Berlyn MKB. Linkage map of Escherichia coli K12, edition 10: the traditional map. Microbiol. Mol Biol Rev. 1998; 62(3): 814-984.

Birnboim HC, Doly J. A rapid alkaline extraction procedure for screening recombinant plasmid DNA. Nucleic Acid Res. 1979; 07: 1513-1523.

Blanc P, Goma G. Propionic acid and biomass production using continuous ultrafiltration fermentation of whey. Biotechnol Lett. 1989;11:189-194.

Blank L, Green J, Guest JR. AcnM of Escherichia coli is a 2-methylcitrate dehydratase (prpD) that can use citratre and isocitrate as substrates. Microbiology. 2002; 148: 133-146.

Brämer C, Steinbüchel A. The methylcitric acid pathway in Ralstonia eutropha: new genes identified involved in propionate metabolism. Microbiology. 2001; 147: 22032214.

Brämer CO, Silva LF, Gomez JGC, Priefert H, Steinbüchel A. Identification of the 2metilcitrate pathway involved in the catabolism of propionate in the polyhydroxyalkanoate producing strain Burkholderia sacchari $\mathrm{IPT} 101^{\mathrm{T}}$ and analysis of a mutant accumulating a copolyester with higher 3-hydroxyvalerate content. Appl Environ Microbiol. 2002; 68: 271-279.

Brämer CO, Vandamme P, Silva LF, Gomez JGC, Steinbüchel A. Burkholderia sacchari sp. nov., a polyhydroxyalkanoate-accumulating bacterium isolated from soil of a sugar-cane plantation in Brazil. Int J Microbiol Ecol. 2001; 51: 1709-1713. 
Brock M, Maerker C, Schütz A, Völker U, Buckel W. Oxidation of propionate to pyruvate in Escherichia coli invovement of methylcitrate dehydratase and aconitase. Eur J Biochem. 2002; 269: 6184-6194.

Bucci DZ. Avaliação de embalagens de PHB (poli (ácido 3-hidroxibutírico)) para alimentos [dissertação]. Santa Catarina: Programa de Pós-Graduação em Engenharia de Produção da Universidade Federal de Santa Catarina; 2003.

Bueno Netto, C.L., Craveiro, A.M., Pradella, J.G.C., Oliveira, M.S., Maiorano, A.E., Pinto, A.G., Saito, R.M. Processo para produzir polihidroxialcanoatos a partir de açúcares extraídos da cana-de-açúcar. Brasil: Patente brasileira PI 9103116-8. 1993.

Byrom D. Industrial production of copolymer from Alcaligenes eutrophus. In: Dawes EA, editor. Novel Biodegradable Microbial Polymers. Netherlands: Dordrecht Kluwer Academic Publishers; 1990. p. 113-117.

Caraschi JC, Leão AL. Propriedades mecânicas dos compósitos poliidroxialcanoato/amido. Em: $5^{\circ}$ Congresso Brasileiro de Polímeros; Águas de Lindoóia; 1999. CD-ROM.

Caraschi JC, Ramos UM, Leão AL. Compostos Biodegradáveis de Polihidributirato (PHB) Reforçado com Farinha de Madeira: Propriedades e Degradação. Acta Scientiarum. 2003; 24(6): 1609-1614.

Carrondo MT, Crespo JPS, Moura MJ. Production of propionic acid using a xylose utilizing Propionibacterium. Appl Biochem Biotechnol. 1988; 12: 295-312.

Chloupková M, Ravn C, Schwartz M, Kraus JP. Changes in the carboxyl terminus of the $\mathrm{b}$ subunit of human propionyl-CoA carboxylase affect the oligomer assembly and catalysis: expression and characterization of seven patient-derived mutant forms of PCC in Escherichia coli. Mol Gen Metab. 2000; 71: 623-632.

Cintra ACSD, Gómez JGC, Silva LF. Clonagem de genes envolvidos no catabolismo de Burkholderia sacchari IPT101. Em: $50^{\circ}$ Congresso Brasileiro de Genética; Florianópolis; 2004. GM 100. CD-ROM

Cintra ACSD, Gómez JGC, Silva LF. Avaliação de mutantes de Burkholderia sacchari pra análise de vias de degradação de ácido propiônico. Em: XXIII Congresso Brasileiro de Microbiologia; Santos; 2005. 22-25 de novembro, Santos, SP

Claes WA, Pühler A, Kalinowski J. Identification of two prpDBC gene clusters in Corynebacterium glutamicum and their involvement in propionate degradation via the 2-methylcitrate cycle. J Bacteriol. 2002; 184: 2728-2739. 
Clarke L, Carbon J. A colony bank containing synthetic ColE1 Hybrid Plasmids representative of the entire E. coli genome. Cell. 1976; 9: 91-99.

de Koning G, Kellerhals M, van Meurs C, Witholt B. Poly(hydroxyalkanoates) from Fluorescent Pseudomonads in Retrospect and Prospect. Journal of Environ Polym Degrad. 1996; 4: 243-252.

de Koning G. Physical Properties of Bacterial Poly((R)-3-hydroxyalkanoates). Can J Microbiol. 1995; 41(01): 303-309.

Doi Y, Kunioka M, Nakamura Y, Soga K. Biosynthesis of copolyesters in Alcaligenes eutrophus H16 from 13C-labelled acetate and propionate. Macromolecules. 1987; 20: 2988-2991.

Ereno D. Plástico renovável. In: Marcolin N et al., editores. Pesquisa FAPESP, São Paulo: Plural editora; 2007. p. 67-71.

Evans CT, Sumegi B, Srere PA, Sherry D, Malloy CR. Propionate oxidation in wildtype and citrate synthase mutant Escherichia coli: evidence for multiple pathways of propionate utilisation. Biochem J.1993; 291: 927-932.

Fenton WA, Rosenberg LE. Disorders of propionate and methylmalonate metabolism. In: Scriver CR, Beaudet AL, Sly WS, Valle D, editors. The Metabolic and Molecular Bases of Inherited Disease, New York: McGraw-Hill Press; 1995.1423-1449.

Fernández-Briera A., Garrido-Pertierra A. A degradation pathway of propionate in Salmonella typhimurium LT-2. BioChimie. 1988; 70: 757-768.

Fernández-Briera A., Garrido-Pertierra A. Studies with Salmonella typhimurium Mutants Defective in Enzymes of the Propionate Catabolism. Current Microbiology. 1989; 19: 169-173.

Filipov MCO, Silva LF, Pradella JGC, Gomez JGC. Peso molecular de poli-3hidroxibutirato produzido por mutantes de Burkholderia sacchari afetados no reconsumo deste polímero biodegradável. Em: XXI Congresso Brasileiro de Microbiologia; Foz do Iguaçu; 2001. Resumos MI 128

Formolo MC, Duarte MAT, Schneider AL, Furlan SA, Pezzin APT. Polihidroxialcanotos: biopoliésteres produzidos a partir de fontes renováveis. Revista Saúde e Ambiente UNIVILLE. 2003; 4: 14-21.

Gerike U, Hough DW, Russell NJ, Dyall Smith ML, Danson MJ. Citrate synthase and 2-methylcitrate synthase: structural, functional and evolutionary relationships. Microbiology. 1998; 144: 929-35. 
Gerngross TU, Slater SC. How green are green plastics? Scientific American Magazine. Ago 2000; 283(2):37-41

Gomez JGC, Bueno Netto CL. Produção de poliésteres bacterianos. In: Almeida Lima et al, editors. Biotecnologia Industrial - Processos Fermentativos e enzimáticos vol. III. São Paulo: Editora Blucher; 2001. p. 219-248.

Gomez JGC. Isolamento e caracterização de bactérias produtoras de polihidroxialcanoatos [dissertação]. São Paulo: Programa de Mestrado em biotecnologia USP-IPT-I. Butantã; 1994.

Gomez JGC, Silva LF, Pradella JGC, Taciro MK, Silva-Queiroz SR, Bretãs AF, Rangel FA, Sánchez R. Explorando o Potencial Metabólico de Bactérias para a Produção de Elastômeros Biodegradáveis. Em: XV SINAFERM Simpósio Nacional de Bioprocessos; Recife; 2005. CD-ROM,

Gomez JGC, Bueno Netto CL. Produção de plásticos biodegradáveis por bactérias. Rev Bras Eng Quim. 1997;17: 24-29.

Gomez JGC, Rodrigues MFA, Alli RCP, Torres BB, Bueno Netto CL, Oliveira MS, Silva LF. Evaluation of soil gram-negative bacteria yielding polyhydroxyalkanoic acids from carbohydrates and propionic acid. Appl Microbiol Biotechnol. 1996; 45: 785-791.

Gomez JGC, Fontolan V, Alli RCP, Rodrigues MFA, Bueno Netto CL, Silva LF, Simões DA. Production of P3HB-co-3HV by soil isolated bacteria able to use sucrose. Rev Microbiol. 1997; 28: 43-48.

Gregório SS, Gómez JGC, Silva LF. Metabolismo de propionato e produção de P3HB-co-3HV em Burkholderia sacchari IPT 101. Em: XXI Congresso Brasileiro de Microbiologia; Foz do Iguaçu; 2001. Resumos MI 124.

Grimek TL, Escalante-Semerena JC. The acnD genes of Shewenella oneidensis and Vibrio cholerae encode a new Fe/S-dependent 2-Methylcitrate dehydratase enzyme that requires prpF function in vivo. Journal Bacteriol. 2004: 186 (2): 454-462.

Grimek TL, Holden H, Rayment I, Escalante-Semerena JC. Residues C123 and D58 of the 2-methylisocitrate Lyase (PrpB) Enzyme of Salmonella enterica are essencial for catalysis. J Bacteriol. 2003; 185: 4837-4843.

Hazer B, Steinbüchel A. Increased diversification of polyhydroxyalkanoates by modification reactions for induatrial and medical applications. Appl. Microbiol. Biotechnol. 2007; 74: 1-12.

Henikoff S, Haughn GW, Calvo JM, Wallace JC. A large family of bacterial activator proteins. Proc. Natl. Acad. Sci. USA. 1988; 85: 6602 -6606. 
Hohn B. DNA as substrate for packaging into bacteriophage lambda, in vitro. J Mol Biol. 1975; 98: 93-106.

Hohn B, Murray K. Packaging Recombinant DNA Molecules into Bacteriophage Particles in vitro. PNAS. 1977; 74(8): 3259-3263.

Holmes PA. Biologically produced PHA polymers and copolymers. In: Bssett DC, editor. Developments in crystalline polymers. London: Elsevier Press; 1988. p.1-65.

Holmes PA. Applications of PHB - a microbially produced biodegradable thermoplastic. Phys Technol. 1985; 16: 32-36.

Horswill AR, Escalante-Semerena JC. Salmonella typhimurium LT2 catabolizes propionate via 2-methtlcitric acid cycle. J Bacteriol.1999; 181 (18): 5615-5623.

Horswill AR, Escalante-Semerena JC. Propionate catabolism in Salmonella typhimurium LT2: two divergently transcribed units comprise the prp locus at 8,5 centisomes, prpR encodes a member of the sigma-54 Family of activators, and the prpBCDE genes constitute na operon. J Bacteriol. 1997; 179 (3): 928-940.

Horswill AR, Escalante-Semerena JC. In vitro conversion of propionate to pyruvate by Salmonella enterica enzymes: 2-methylcitrate dehydratase (prpD) and aconitase enzymes catalyze the conversion of 2-methylisocitrate. Biochemistry. 2001; 40 (15): 4703-4713.

Horswill AR, Escalante-Semerena JC. Characterization of the Propionyl-CoA Synthetase (PrpE) enzyme of salmonella enterica: residue Lys592 is Required for propionyl-AMP synthesis.Biochemistry. 2002; 41: 2379-2387.

ISBP International Symposium on Bacterial Polyhydroxyalkanoates ISBP'2002, Münster, Alemanha, setembro, 2002, Abstract Book

Kadouri D, Jurkevitch E, Okon Y, Castro-Sowinski S. Ecological and agricultural significance of bacterial polyhydroxyalkanoates. Crit Rev Microbiol. 2005; 31: 55-67.

Kahar P, Tsuge T, Taguchi K, Doi Y. High yield productin of polyhydroxyalkanoates from soybean and oil by Ralstonia eutropha and its recombinant srain. Polym Degrad Stabil. 2004; 83: 79-86.

Kay W. Genetic control of the metabolism of propionate by Escherichia coli K12. Biochem Biophys Acta. 1972;.264: 508-521.

Kim JH, Kim BG, Choi CY. Effect of propionic acid on poly ( $\beta$-hydroxybutyric-co- $\beta$ hydroxyvaleric) acid production by Alcaligenes eutrophus Biotechnol. Lett. 1992; 14 (10): 903-906. 
Knauf WW, Nester EW. Wide host range clonin vectors: a cosmid cloning bank from an Agrobacterium Ti plasmid. Plasmid. 1982; 8: 45-54.

Kovach ME, Phillips RW, Elzer PH, Roop RM, Peterson KM. pBBR1MCS: a broadhost-range cloning vector. Biotechniques. 1994; 16(5): 800-802.

Kovach ME, Elzer PH, Hill DS, Robertson GT, Farris MA, Roop RM, Peterson KM. Four new derivatives of the broad host-range cloning vetor $\mathrm{p}$ BBR1MCS, carrying different antibiotic-resistance cassettes. Gene. 1995; 166: 175-176.

Kroeger M, Wahl R. Compilation of DNA sequences of Escherichia coli K12: description of the interactive databases ECD and ECDC (update 1996). Nucleic Acid Res. 1997; 25: 39-42.

Kumari S, Tishel R, Eisenbach M, Wolf AJ. Cloning, characterization and functional expression of acs, the gene which encodes acetyl coenzyme A synthetase in Escherichia coli. J Bacteriol. 1995; 177(10): 2878-2886.

Lee SK, Newman JD, Keasling JD. Catabolite repression of propionate catabolic genes in Escherichia coli and Salmonella enterica: evidence for involviment of the cyclic AMP receptor protein. J Bacteriol. 2005; 187(8): 2793-2800.

Li R, Zhang H, Qi Q. The production of polyhydroxyalkanoates in recombinant Escherichia coli. Biores Technol. 2007; 98: 2312-2320.

London RE, Allen DL, Gabel SA, DeRose E. Carbon-13 nuclear magnetic resonance study of metabolismo of propionate by Escherichia coli. J Bacteriol. 1999; 181(11): 3562-3570.

Lopes MSG, Cintra ACSD, Gómez JGC, Silva LF. Avaliação de linhagens recombinantens para a produção de plástico biodegradável a partir de bagaço de canade-açúcar. Em: Seminário de hidrólise enzimática de biomassas (SHEB); Maringá; 2005. Resumo CD-ROM

Madison LL, Huisman FW. Metabolic engineering of poly(3-hydroxyalkanoates): from DNA to plastic. Microbiol Mol Biol Rev. 1999; 63: 21-53.

Maerker C, Rohde M, Brakhage AA, Brock M. Methylcitrate synthase from Aspergillus fumigatus. Propionyl-CoA affects polyketide synthesis, growth and morphology of conidia. FEBS J. 2005; 272(14):3615-3630.

Muñoz-Elias EJ, Upton AM, Cherian J, McKinney JD. Role of the methylcitrate cycle in Mycobacterium tuberculosis metabolism, intracellular growth, and virulence. Mol Microbiol. 2006; 60(5):1109-1122. 
Nonato RV, Mantelatto PE, Rossell CEV. Integrated production of biodegradable plastic, sugar and ethanol. Appl Microbiol Biotechnol. 2001; 57: 1-5.

Oeding V, Schlegel H. $\beta$-ketothiolase from Hydrogenomonas eutropha H-16 and its significance in the regulation of poly-b-hydroxybutyrate metabolism. Biochem $\mathrm{J}$. 1973; 134: 239-248.

Pachekoski WM, Rosário F, Ezquerra TA, Agnelli JAM. Caracterização da degradação do polihidroxibutirato processado. Em: $7^{0}$ Congresso Brasileiro de Polímeros; Minas Gerais; 2003. p 210-211

Palácios S, Escalante-Semerena JC. 2-Methylcitrate-dependent activation of the propionate catabolic operon (prpBCDE) of Samonella enterica by PrpR protein. Microbiology. 2004; $150: 3877-3887$.

Palacios S, Starai VJ, Escalante-Semerena JC. Propionyl Coenzyme A is a common intermediate in the 1,2-propanediol and propionate catabolic pathways needed for expression of the $\operatorname{prpBCDE}$ operon during growth of salmonella enterica on 1,2propanediol. J Bacteriol. 2003; 185: 2802-2810.

Pereira, E.M. (2002) Clonagem de genes da via de 2-metilcitrato sintase do catabolismo de propionato em Burkholderia sacchari e obtenção de mutantes por recombinação homóloga mais eficientes para a produção de polímero biodegradável, proc. FAPESP 00/00690-7, relatório final.

Pereira EM. Clonagem de genes do ciclo de 2-metilcitrato e avaliação de estratégias para a obtenção de mutantes prp de Burkholderia sacchari, produtora de plástico biodegradável. [dissertação]. São Paulo: Programa de Pós-Graduação Interunidade em Biotecnologia USP/IPT/Inst. Butantan; 2003.

Pereira EM. Avaliação da influência de genes do catabolismo de propionato sobre a síntese de copolímero biodegradável em Burkholderia sacchari e outras bactérias [dissertação]. São Paulo: Programa de Pós-graduação Interunidades em Biotecnologia USP IPT - Inst. Butantan; 2007.

Pereira EM, Gómez JGC, Silva LF. Análise molecular e avaliação da capacidade produtora de biopolímero em mutantes prp de Burkholderia sacchari. Em: SINAFERM 2005 Simpósio Nacional de Bioprocessos; Recife; 2005. 2-5 de agosto de 2005

Pereira EM, Silva LF, Gómez JGC. Clonagem de genes e obtenção de mutantes de Burkholderia sacchari por recombinação homóloga mais eficientes na produção de plástico biodegradável. Em: XXI Congresso Brasileiro de Microbiologia; Foz do Iguaçu; 2001. outubro, Resumos MI 001. 
Pieper U, Steinbuchel A. Identification, cloning and sequence analysis of the poly(3hydroxyalkanoic acid) synthase gene of the Gram positive bacterium Rhodococcus rubber. FEMS Microbiol Lett. 1992; 96: 73-80.

Poirier Y, Nawrath C, Somerville C. Production of polyhydroxyalkanoates, a family of biodegradable plastics and elastomers in bacteria and plants. Bio/Technology. 1995; 13: 142-150.

Poirier Y, Dennis D, Klomparen K, Somerville C. Polyhydroxybutyrate, a biodegradable thermoplastic, produced in transgenic plants. Science. 1992; 256: 520523.

Pradella, J.G.C. (2006) http://www.anbio.org.br/pdf/2/tr06 biopolimeros.pdf, acesssada em Agosto 2006

Pronk JT, Van Der Linden-Beuman A, Verduyn C. Propionate metabolism in Saccharomyces cerevisiae: implications for the metabolon hypothesis. Microbiology. 1994; 140: 717-722.

Quental AC, Felisberti MI. Comportamento térmico e morfológico do polihidroxibutirato - PHB. Em: $6^{\circ}$. Congresso Brasileiro de Polímeros; Gramado; 2001. p 1260-1263

Raecker MO, Bern CJ, Johnson LA, Glatz BA. Preservation of high-moisture maize by various propionate treatment. Cereal Chemistry. 1992; 69: 66-69.

Reeves HC, Stahl WJ, Ajl SJ. $\alpha$-hydroxyglutarate: product of an enzymatic betacondensation between glyoxylate and propionyl-coenzyme A. J Bacteriol. 1963; 86(6): 1352-1353.

Rehm BH, Steinbüchel A. Biochemical and gnetic analysis of PHA synthases and other proteins required for PHA synthesis. Int J Biol Macromol. 1999; 25: 3-19.

Rhie HG, Dennis D. The funtion of ackA and pta genes is necessary for poly(3hydroxybutyrate-co-3hydroxyvalerate) synthesis in recombinant $\mathrm{pha}^{+}$Escherichia coli. Can J Microbiol. 1995a; 41: 200-206.

Rhie HG, DennisD. Role of fadR and atoC(Con) mutations in poly(3hydroxybutyrate-co-3hydroxyvalerate) synthesis in recombinant $\mathrm{pha}^{+}$Escherichia coli. Appl Environ Microbiol. 1995b; 61: 2487-2492.

Riis V, Mai W. Gas chromatography degtermination of poly-b-hydroxybutyric acid in microbial biomass-ester hydrochloric acid propanolysis. J Chomatogr. 1988; 445: 285-289. 
Rocha RCS, Taciro MK, Silva LF, Pradella JGC. Feeding strategy for production of poly(3-hydroxybutyrate-co-3-hydroxyvalerate) $\mathrm{P}(3 \mathrm{HB}-c o-3 \mathrm{HV})$ with Burkholderia sacchari IPT 189. In: European Symposium on Biochemical Sciences ESBES-4 Life: Science and Technology. 2002. Delft University of Technology, The Netherlands, Book of abstracts, p. 174.

Rocha RCS. Produção de poli-3-hidroxibutirato-co-3-hidroxivalerato por Burkholderia sacchari IPT 189 [dissertação]. São Paulo: Programa de Mestrado em biotecnologia USP-IPT-I Butantã; 2002.

Rocha RCS, SilvaLF, Taciro MK, Pradella JGC. Production of poly(3hydroxybutyrate-co-3-hydroxyvalerate) $\mathrm{P}(3 \mathrm{HB}-\mathrm{co}-3 \mathrm{HV})$ with a broad range of $3 \mathrm{HV}$ content at high yields by Burkholderia sacchari IPT 189. World J Microbiol Biotechnol.2007.

Rodríguez RJ, Gómez JGC, Silva LF, Taciro MK, Pradela JGC. Biosynthesis and Characterzation of medium-chain-length Polyhydroxy- Alkanoic Acids (PHAMCL) produced by Pseudomona putida IPT 046 from carbohydrates.European Polymer Journal. 2003; 39: 1385-1394.

Sambrook J, Fritsch EF, Maniatis T. Molecular cloning: a laboratory manual. New York: Cold Spring Harbor Lab Press; 1989.

Sartori DM. Obtenção de um mutante de Alcaligenes eutrophus melhorado geneticamente para a produção do co-polímero polihidroxibutiratopolihidroxivalerato (PHB-PHV) [dissertação]. São Paulo: Programa de Mestrado em Microbiologia do Instituto de Ciências Biomédicas da Universidade de São Paulo; 1998.

Scalenghe F, Turco E, Edstrom JE, Pirrotta V, Melli MI. Microdissection and cloning of DNA from a specific region of Drosophila melanogaster polytene chromosomes. Chromosoma 82. 1981; 82 (2): 205-216.

Senior PJ, Dawes EA. The regulation of poly-b-hydroxybutyrate metabolism in Azotobacter beijerinckii. Biochem J. 1973;134: 225-238.

Silva LF. Estudo do catabolismo de propionato em Burkholderia sp visando o aumento da eficiência na produção de poli-3-hidroxibutirato-co-3-hidroxivalerato (P3HB-co-3HV) - um plásticobiodegradável [dissertação].São Paulo: Programa de doutorado em Microbiologia apresentada ao ICB USP; 1998.

Silva LF, Gomez JGC. Cepa mutante de Burkholderia sp e método de obtenção da cepa. Brasil: Patente. PI 9806557-2. 1998 
Silva LF. Development of technology at IPT to produce biopolymers from sugar cane. In: $2^{\text {o. }}$ Congreso Internacional de Microbiología Industrial; Bogotá; 2000. Colômbia. (2000)

Silva LF, Gomez JGC, Oliveira MS, Torres BB. Propionic acid metabolism and poly3-hydroxybutyrate-co-3-hydroxyvalerate (P3HB-co-3HV) production by Burkholderia sp. J Biotechnol. 2000; 76: 165-174.

Silva LF, Taciro MK, Michelin ME, Carter JM, Pradella JGC, Gomez JGC. Process development for poly-3-hydroxybutyrate ( $\mathrm{P} 3 \mathrm{HB})$ production from sugar cane bagasse hydrolysate. In: International Symposium on Biological Polyesters ISBP. 2002. Westfälische Wilhelms-Universität Münster, Germany, Book of Abstracts SL 08, p. 64.

Silva LF, Gomez JGC, Oliveira MS, Alterthum F. Freeze-drying of industrial yeast strains: influence of growh conditions, cooling rates and suspending media on the viability of recovered cells. Rev Microbiol. 1992; 23(2): 117-122.

Silva LF, Gomez JGC, Rocha RCS, Taciro MK, Pradella JGC. Produção biotecnológica de poli-hidroxialcanoatos para a geração de polímeros biodegradáveis no Brasil. Quím Nova. 2007; 30 (7): 1732-1743

Silva LF, Rodrigues MFA, Gomez JGC. Biodiversidade brasileira é fonte de microorganismos produtores de pásticos e elastômeros biodegradáveis, ComCiência Biodiversidade, http://www.comciencia.br/reportagens/biodiversidade/bio15.htm, acessado em 02/01/02,11:44h.

Silva LF, Taciro MK, Michelin MER, Carter JM, Pradella JGC, Gomez JGC. Poly-3hydroxybutyrate (P3HB) production by bacteria from xylose, glucose and sugarcane bagasse hydrolisate. J Ind Microbiol Biotechnol. 2004; 31: 245-254.

Silva LF, Taciro MK, Pradella JGC, Gómez JGC. Fábrica viva de plástico biodegradável. Ciência Hoje. 2001b; 174: 69-71.

Silva LF, Gomez JGC, Oliveira MS, Torres BB. Propionic acid metabolism and poly3-hydroxybutyrate-co-3-hydroxyvalerate (P3HB-co-3HV) production by Burkholderia sp. J Biotechnol. 2000; 7: 165-174.

Silva LF, Gomez JGC, Oliveira RC, Rodrigues MFA, Bueno Netto CL, Steinbüchel A, Torres BB. Reduction costs of $\mathrm{P} 3 \mathrm{HB}-\mathrm{co}-3 \mathrm{HV}$ production using mutants showing higher Y3HV/Prop. In: International Symposium on Bacterial Polyhydroxyalkanoates: program and book of abstracts; Davos; 1996. : ISBP, p. 8/03. 
Simon R, Priefer U, Pühler A. A broad host range mobilisation system for in vivo genetic engineering: transposon mutagenesis in gram negative bacteria. Bio/Technology. 1983; 1: 784-91.

Slater S, Mitsky TA, Houmiel KL, Hao M, Reiser SE, Taylor NB, Tran M, Valentin HE, Rodriguez DJ, Stone DA, Padgette SR, Kishore G, Gruys KJ. Metabolic engineering of Arabidopsis and Brassica for poly(3-hydroxybutyrate-co-3hydroxyvalerate) copolymer production. Nature Biotechnology. 1999; 17.

Slater S, Houmiel KL, Tran M, Mitsky TA, Taylor NB, Padgette SR, Gruys KJ. Multiple $\beta$-Ketothiolases Mediate Poly ( $\beta$-Hydroxyalkanoate) Copolymer Synthesis in Ralstonia eutropha. J Bacteriol. 1998; 180 (8): 1979-1987.

Sprat SK, Ginsburgh CL, Nunn WD. Isolation and characterisation of Escherichia coli mutants defective in propionate metabolism. J Bacteriol. 1981; 146: 1166-1169.

Stams AJM, Dijkema C, Plugge CM, Lens P. Contribution of ${ }^{13} \mathrm{C}-\mathrm{NMR}$ spectroscopy to the elucidation of pathways of propionate formation and degradation in methanogenic environments. Biodegradation. 1998; 9: 463-473.

Starai VJ, Celic I, Cole RN, Boeke JD, Escalante-Semerena JC. Sir2-Dependent activation of acetyl-CoA synthetase by deacetylation of active Lysine. Science. 2002; 298: 2390-2392.

Starai VJ, Takahashi H, Boeke JD, Escalante-Semerena JC. Short-Chain fatty acid activation by acyl-Coenzyme A synthetase requires SIR2 Protein function in Salmonella enterica e Saccharomyces cerevisiae. Genetics. 2003; 163: 545-555.

Steinbüchel A. Polyhydroxyalkanoic acids. In: Byrom D, editor. Biomaterials Novel materials from biological sources, London: Macmillan Publishers Ltd; 1991. p. 123213.

Steinbuchel A, Hein S. Biochemical and molecular basis of microbial synthesis of polyhydroxyalkanoates in microorganisms. Adv Biochem Eng Biotechnol. 2001; 71: 81-123.

Steinbüchel A, Valentin HE. Diversity of bacterial polyhydroxyalkanoic acids. FEMS Microbiol Lett. 1995; 128: 219-228.

Sudesh K, Taguchi K, Doi Y. Can cyanobacteria be a potential PHA producer? RIKEN Review Ecomolecular Science Research. 2001; 42: 75-76.

Suryianmongkol P, Weselake R, Narine S, Moloney M, Shah S. Biotechnological approaches for the production of polyhydroxyalkanoates in microorganisms and plants. A review Biotechnol Adv. 2007; 25: 148-175. 
Tabuchi T, Serizawa N, Uchiyama H. A novel pathway for the partial oxidation of propionyl-coA to pyruvate via seven-carbon tricarboxylic acids in yeasts. Agr Biol Chem. 1974; 38 (12): 2571-2572.

Tabuchi T, Uchiyama H. Methylcitrate condensing and methylisocitrate cleaving enzymes: evidence for the pathway of oxidation of propionyl-CoA to pyruvate via C7-tricarboxylic acids. Agric Biol Chem. 1975; 39: 2035-2042.

Textor S, Wendish VF, De Graaf A, Müller U, Linder MI, Linder D, Buckel W. Propionate oxidation in Escherichia coli: evidence for operation of a methylcitrate cycle in bacteria. Arch Microbiol. 1997; 168: 428-436.

Tholozan JL, Samain E, Grivet JP, Albagnac G. Propionate metabolism in a methanogenic enrichment culture. Direct reductive carboxylation and acetogenesis pathway. FEMS Microbiol. 1990.; 73: 291-298.

Tsang AW, Horswill AR, Escalante-Semerena JC. Studies of regulation of expression of the propionate ( $r p \mathrm{BCDE}$ ) operon provide insights into how Salmonella typhimurium LT2 integrates its 1,2-propanodiol and propionate catabolic pathway. J Bacteriol. 1998; 180 (24): 6511-6518.

Tsang A.W, Escalante-Semerena JC. $\operatorname{cobB}$ function is requered for catbolism of propionate in Salmonella typhimuriu LT2: Evidence for Existence of a substitute function for CobB within the 1,2-Propanediol utilization $(p d u)$ operon. J Bacteriol. 1996; 178: 7016-7019.

Ugarte M, Pérez-Cerdá C, Rodriguez-Pombo P, Desviat LR, Pérez B, Richard E, Muro S, Campeau E, Ohura T, Gravel RA. Overview of mutations in the PCCA and $P C C B$ genes causing propionic academia. Human Mut. 1999; 14(4): 275-282.

Valappil SP, Misra SK, Boccaccini A, Roy IBiomedical applications of polyhydroxyalkanoates, an overview of animal testing and in vivo responses. Exp Rev Med Dev. 2006; 3(6): 853-868.

Valentin HE, Dennis D. Metabolic pathway for poly-3-hydroxybutyrate-co-3hydroxyvalerate formation in Nocardia corallina: inactivation of mut $B$ by chromosomal integration of kanamycin resistancegene. Appl Environ Microbiol. 1996; 62: 371-373.

Wegener WS, Reeves HC, Aij SJ. Propionate metabolism I. Factors regulating adaptation of Escherichia coli to propionate. Arch Biochem Biophys. 1968; 123: 5561.

Wegener WS, Reeves HC, Rabin R, Ajl SJ. Alternate pathways of metabolism of short-chain fatty acids. Bacteriological Rev. 1968; 32: 1-26. 
Zaim J, Kierzek AM. The structure of full-length LysR-type transcriptional regulators. Modeling of the full-length OxyR transcription factor dimer. Nucleic Acids Research. 2003; 31 (5). 